\title{
A PROPÓSITO DE UN ELEMENTO ESENCIAL DE LA DEFENSA DE LA COMPETENCIA EN EUROPA: LAS FACULTADES DE INVESTIGACIÓN DE LA COMISIÓN EN MATERIA DE INSPECCIÓN
}

\author{
Jesús Alfonso Soto PinedA \\ Docente investigador del Departamento de Derecho económico \\ de la Universidad Externado de Colombia
}

\begin{abstract}
RESUMEN
En base a la prolongación de las facultades de investigación que le ban sido proporcionadas a la Comisión Europea para combatir la existencia de acuerdos colusorios en el ámbito comunitario, el presente artículo expone las condiciones en las cuales el poder percibido con mayor sensibilidad desde el terreno empresarial, la inspección, debe ser puesto en marcha por la máxima autoridad comunitaria de competencia, analizando en detalle la contradicción natural que se presenta entre los objetivos propios de la inspección y dos postulados básicos relacionados con el derecho de defensa, como lo son el secreto profesional y el derecho a guardar silencio o no autoinculparse.
\end{abstract}

Palabras clave: Comisión Europea, defensa de la competencia, facultades de investigación, inspección, secreto profesional, autoincriminación.

\section{ABSTRACT}

On the basis of the extension of the faculties assigned to the EU Commission to fight the existence of collusive agreements within the eurozone, the current article shows the requirements in which the power to inspect, seen more sensitively within the business world, must be started up by the European Competition Authority while looking into the natural contradiction from the inspection's own objectives and the two basic postulates related to the right of defense as are the professional secret and the right to remain silent or against self-incrimination.

keywords: European Commission, Defense of Competition, Research Faculties, Inspection, Professional Secret, Self-Incrimination.

\section{ZUSAMMENFASSUNG}

Auf der Grundlage der Erweiterung der Untersuchungsbefugnisse, die der EUKommisssion erteilt wurden, um die Existenz von Kollusionsvereinbarungen im EU-Rabmen zu bekämpfen, stellt der vorliegende Artikel die Bedingungen vor, unter denen die oberste kompetente EU-Instanz ibre Außenprüfungen, die seitens 
der Unternebmer kritisch beäugt werden, durchführen muss. Es wird im Einzelnen der natürliche Widerspruch untersucht, der sich zwischen den Prüfungsabsichten der EU-Kommission und den beiden Grundpostulaten des Rechts auf Verteidigung zwangsläufig ergibt: Dem Berufsgeheimnis und dem Recht auf Aussageverweigerung bzw. der Verweigerung der Selbstbeschuldigung.

Schlüsselwörter: Europäische Kommission, Verteidigung der Kompetenz, Untersuchungsbefugnisse, Außenprüfung, Berufsgeheimnis, Selbstbeschuldigung.

SUMARIO: I. INTRODUCCIÓN.-II. A PROPÓSITO DE LA INSPECCIÓN EN SEDE EMPRESARIAL.-III. LA PROLONGACIÓN DE LA FACULTAD DE INSPECCIÓN.-IV. EL SECRETO PROFESIONAL Y SU AGITADA RELACIÓN CON LAS FACULTADES DE INSPECCIÓN DE LA COMISIÓN.-V. LA EXISTENCIA Y DESARROLLO DEL PRIVILEGIO.-VI. CONFIDENCIALIDAD Y USO DEL MATERIAL RECABADO POR LA COMISIÓN.-VII. EL DERECHO A GUARDAR SILENCIO Y A NO AUTOINCRIMINARSE EN EL CURSODE UNA INVESTIGACIÓN DE LA COMISIÓN EUROPEA EN MATERIA DE COMPENTENCIA._-VIII. CONCLUSIONES.-IX. BIBLIOGRAFÍA.

\section{INTRODUCCIÓN}

Una parte importante de los medios con que cuenta la Comisión Europea para proteger al mercado comunitario y a la libre competencia en Europa es la atribución que le otorga el núm. 1 del art. 20 del Reglamento $1 / 2003$, la cual le da el poder para llevar a cabo todas las inspecciones de empresas y asociaciones de empresas que sean necesarias para «desmantelar» y llevar a su fin todas aquellas conductas transgresoras de las normas antitrust comunitarias.

La presente facultad, al igual que muchas otras relacionadas con el proceso investigador, decisorio y sancionatorio de la máxima autoridad comunitaria de la competencia, la Comisión, es una manifestación de la evolución y de una mejora en favor de la modernización de la defensa de la competencia que el legislador europeo ha hecho del «poder de verificación» que desarrollaba el Reglamento 17/1962 en su art. 14; generando así una ampliación significativa de los poderes de la autoridad comunitaria para defender el proceso competitivo en el seno de la Unión Europea y a sus participantes ${ }^{1}$.

\footnotetext{
${ }^{1}$ Jose Luis GIL IBÁÑEZ, «La Comisión y la aplicación del Derecho comunitario de la competencia», en Luis GARRIDO EsPÁ (ed.), La defensa de la competencia por los órganos judiciales: el Reglamento (CE) 1/2003, Madrid, Consejo General del Poder Judicial, 2005, p. 124.
} 
El objetivo de la inspección en estudio es poder descubrir por medio de la sorpresa a aquellos responsables de las distorsiones que se presenten en el mercado ${ }^{2}$; quienes, conscientes de que aquello que están realizando es contrario a las normas de libre competencia, buscan hacer «desaparecer» cualquier evidencia de sus actividades ilícitas³.

Poner en marcha mecanismos de choque que permitan a la Comisión sacar a flote un secreto de unos pocos que perjudica a muchos ${ }^{4}$, tal y como se suscita en aquellos casos en los cuales las empresas ponen en marcha actuaciones colusorias, se logra, en parte, gracias al poder mencionado, toda vez que, en razón de él, la autoridad podrá conducir inspecciones en la sede y establecimientos de la empresa o empresas investigadas, e incluso en otros sitios, como lo pueden ser las residencias particulares de personas vinculadas con la empresa (lo cual es un aporte de importancia del art. 21

${ }^{2}$ Es posible que el descubrimiento de la conducta llegue también como resultado de una inspección realizada a una empresa o a una asociación de empresas previamente pactada por la «inspeccionada» y por la Comisión, y en la cual la primera, por tanto, esté ampliamente enterada de su acaecimiento. No siendo entonces, en ningún caso, obligatoria la sorpresa para que la inspección tenga un resultado positivo para la protección de las normas de libre competencia. Como así puede extraerse de Richard Whish, Competition Law, London, Oxford University Press, 2008, p. 269.

3 Hace énfasis en el descubrimiento in fraganti de las conductas y entiende que, en todo caso, la atribución mencionada, la cual llama redada e inspección sorpresa, se justifica en el imprevisto que se debe añadir a su puesta en marcha, pues, en caso contrario, no cuenta con el mismo sentido de la eficiencia. Vid. Richard Whish, Competition Law, op. cit., p. 269. Lo cual es matizado por Valentine KorAH, An introductory guide to EC Law and practice, Oxford-Portland, Hart Publishing, 2007, p. 265, quien entiende que el proceso de investigación se ve igualmente enriquecido con la inspección, así sea previamente notificada a la empresa o asociación de empresas, toda vez que dicha noticia, en la práctica, genera reacciones de la inspeccionada, quien, sin importar que la diligencia aún esté por realizarse, puede poner de manifiesto a la Comisión acerca de concepciones equivocadas que se tienen sobre algunos aspectos o puede simplemente anexar pruebas que acreditan su no implicación en lo investigado.

${ }^{4}$ Es necesario, máxime cuando normalmente, en razón de la envergadura de las empresas involucradas en el acuerdo anticompetitivo, así como también como resultado de la estabilidad de los mismos, se impide la labor de verificación, tanto en los casos en los cuales se esté frente a uno de los llamados cárteles duros, o de ciertas actuaciones e infracciones de gran talante, haciendo necesario que una autoridad de corte administrativo, nacional o comunitaria, sea la única con posibilidad de comprobar el acaecimiento de la conducta contra legem. Vid. Stephan POLSTER, «Access to cártel evidence as a key to enhanced private enforcement: The Austrian example», Chambers client report, núm. 25 (2008). Siendo igualmente relevantes los comentarios de Ilya R. Segal y Michael Whinston, «Public vs. private enforcement of antitrust law: A Survey», Working paper, núm. 335 (2006), p. 5 (el documento está disponible para consulta en bttp://papers.ssrn.com/sol3/papers. \%20cfm?abstract \%20 $i d=952067$ ). Complementado, a su vez, por David Crane, «Private enforcement against international cárteles in Latin America: a US Perspective», en Competition law and policy in Latin America, Oxford, Hart Publishing, 2009, p. 327. 
del Reglamento 1/2003), en los vehículos de los directivos normalmente asociados a este tipo de conductas colusorias, así como en residencias de familiares cercanos o similares, en aquellos casos en los que las infracciones a los arts. 101 y 102 del Tratado sean de extrema gravedad ${ }^{5}$.

Una vez otorgada la facultad en términos genéricos en su núm. 1, el núm. 2 del art. 20 detalla los poderes que tienen los oficiales y las personas facultadas por la Comisión para conducir la inspección ${ }^{6}$, y en su núm. 3 enuncia las condiciones en las cuales dichos poderes deben ser ejerci$\operatorname{dos}^{7}$. A continuación, por tanto, se hará un análisis de las condiciones que envuelven la facultad mencionada y se resaltarán ciertos aspectos que se entienden como controvertidos.

\section{A PROPÓSITO DE LA INSPECCIÓN EN SEDE EMPRESARIAL}

De los textos mencionados en el apartado introductorio del presente artículo se extrae que, en virtud de las facultades en materia de inspección, los agentes de la autoridad comunitaria, en el curso de una pesquisa en sede corporativa, podrán acceder a los emplazamientos empresariales, estando capacitados para movilizarse dentro de ellos, para solicitar la muestra de lugares específicos dentro de las instalaciones, para requerir la exhibición de los documentos o similares que estimen pertinentes para aclarar la presunta infracción, y, en fin, para, siempre en términos de anuencia y

${ }^{5}$ El mencionado art. 21, núm. 1, justifica dicha posibilidad en los siguientes términos: «Para demostrar una infracción grave del art. 81 o del art. 82 del Tratado, la Comisión podrá ordenar, mediante decisión, que se realice una inspección en esos locales, terrenos y medios de transporte».

${ }^{6}$ Que de forma textual se aporta por su relevancia, expresando que podrán: «a) acceder a todos los locales, terrenos y medios de transporte de las empresas y asociaciones de empresas; b) examinar los libros y cualquier otra documentación profesional, cualquiera que sea su soporte material; $c$ ) hacer $\mathrm{u}$ obtener copias o extractos en cualquier formato de dichos libros o de la documentación; $d$ ) colocar precintos en cualquiera de los locales y libros o documentación de la empresa durante el tiempo y en la medida necesarios para la inspección; e) solicitar a cualquier representante o miembro del personal de la empresa o de la asociación de empresas explicaciones sobre hechos o documentos relativos al objeto y la finalidad de la inspección y guardar constancia de sus respuestas».

7 Donde, en resumen, se establece una obligación de: i) informar a la autoridad de competencia del país miembro acerca de la inspección a realizar; ii) presentar una orden escrita donde se expresen: $a$ ) la finalidad de la diligencia, $b$ ) el objeto de la misma y $c$ ) las sanciones del art. 23 del Reglamento que serán impuestas ante aportación incompleta de documentos o respuestas inexactas o engañosas del personal de la empresa. 
no de imposición, llevar a cabo la diligencia en búsqueda del mayor número de pruebas, toda vez que, si bien están autorizados para poner en marcha este instrumento de investigación, los miembros de la Comisión no tienen la facultad de lograr sus propósitos con el uso de la fuerza ${ }^{8}$.

A su vez, merced a la facultad enunciada, los oficiales comunitarios tienen autorización para examinar libros y documentos, sea cual sea su soporte $^{9}$, sacar fotocopias de ellos o de ciertos apartes de interés, para colocar precintos en lugares y documentos cuando lo estimen pertinente ${ }^{10}$, así como para preguntar al personal de la «inspeccionada» y grabar sus respuestas cuando necesiten explicaciones acerca de hechos o documentos relacionados con la materia y propósitos de la diligencia ${ }^{11}$.

La inspección, en términos similares a los de otra facultad de importancia de la Comisión, como lo es la de solicitar en el curso de una investigación información a una empresa o asociación de empresas ${ }^{12}$, puede nacer

${ }^{8}$ La fuerza sólo podrá ser utilizada en los casos en los cuales la oposición de la empresa o asociación de empresas venga en el escenario de una inspección basada en una decisión, pues ahí la Comisión podrá solicitar la asistencia del Estado para que le colabore en su puesta en marcha; no implicando, por tanto, la utilización de la fuerza por parte de los agentes, sino por parte de las fuerzas del Estado que asisten a estos últimos. Aspecto sobre el cual se ahondará más adelante dentro de la presente sección y que se encuentra claramente descrito en el fallo Hoechst A. G. vs. Comisión, en sus apartados 31 y 32.

${ }^{9}$ Facultad que tenía un precedente claro en el letra a) del núm. 1 del art. 14 del Reglamento 17/1962, en el cual se leía que en la verificación la Comisión tenía el poder de «controlar los libros y demás documentos profesionales». Poder que se ha visto correctamente complementado con el Reglamento 1/2003, en razón de ser una adaptación a los múltiples medios y soportes en los cuales puede encontrarse el material documental y a los cuales, gracias a esta atribución, puede acceder la Comisión.

${ }^{10}$ Sobre este poder se expresan Alison Jones y Brenda SufRIn, EC Competition Law. Text, Cases and Material, New York, Oxford University Press, 2008, p. 1162, poniendo de manifiesto que, si bien hasta ahora se incluye dentro de las atribuciones de la Comisión, esta facultad ya venía siendo una práctica común que en el marco actual, gracias a lo dispuesto en el Reglamento 1/2003, se encuentra mejor regulada, toda vez que el núm. 25 del Reglamento deja claro que dichos precintos normalmente no deberán ser impuestos por más de setenta y dos horas, y la letra $e$ ) del núm. 1 del art. 23 otorga el poder de imposición de multas cuando sean vulnerados.

${ }^{11}$ No está de acuerdo con esta atribución y la crítica de forma acentuada Mario SIRAGUSA, «A critical review of the white paper on the reform of the EC Competition Law Enforcement rules», en Barry E. HawK (ed.), 1999 Proceedings of the Fordham Corporate Law Institute, New York, Juris Publishing, 2000, pp. 295-301.

${ }_{12} \mathrm{Al}$ respecto, Christopher Bellamy, Graham Child y Enric Picañol, Derecho de la competencia en el mercado común, Madrid, Civitas, 1992, p. 680; Antonio Creus CARRERAS y Olivia Amador Peñate, «Procedimiento administrativo ante la Comisión Europea y control jurisdiccional del TJCE», en José María Beneyto Pérez-Cerdá y Jerónimo Maillo GonZÁlez Orús (dirs.), Tratado de Derecho de la Competencia. Unión Europea y España, t. II, Madrid, Bosch, 2005, pp. 758-760. 
de una autorización simple ${ }^{13}$ o de una decisión en firme ${ }^{14}$, conllevando en ambos casos condiciones y consecuencias dispares para la Comisión y para la «inspeccionada».

La doctrina, más allá de las diferencias que comportan las dos modalidades enunciadas, ha entendido que en ambos casos la solicitud ${ }^{15}$ debe nacer de una necesidad real por parte de la Comisión, quien debe asumir como posibles ciertos efectos que se presumen deben resultar de la diligencia; siendo, por tanto, necesario demandar siempre a aquella autoridad la realización de un «examen» interno del cual se infiera, así sea de la forma más etérea, cuál es la relación que tiene la diligencia a realizar con la infracción a las normas de libre competencia ${ }^{16}$, para de dicha forma facilitar el sustento de la petición ${ }^{17}$, sea cual sea el formato elegido.

13 La cual debe en todo caso contener de forma similar o equivalente los mismos aspectos que le son requeridos al mandamiento simple, por el cual la Comisión requiere información, contenidos en el art. 18, núm. 2, del Reglamento 1/2003.

${ }^{14}$ Respecto de esta modalidad llama la atención el cambio aportado por el Reglamento $1 / 2003$, que generó una variación de lo que establecía el art. 11 del Reglamento 17/1962, toda vez que, bajo la vigencia de este último, la Comisión sólo podía hacer uso de esta facultad por medio de una decisión en firme de la Comisión en los casos en los cuales la empresa hubiese, previamente, rehusado a cooperar valiéndose únicamente de un requerimiento simple. Aspecto que con la evolución aportada por el Reglamento 1/2003 otorgó una liberación a la Comisión, quien se vio así facultada para solicitar información o para poner en marcha una inspección por medio de una solicitud simple, incluso si previamente no se había hecho solicitud alguna a la empresa. Vid. Jesús Alfonso Soto PINEDA, Vías de aplicación del Derecho de la competencia, Madrid, Universidad Autónoma de Madrid, 2012, p. 113.

${ }^{15}$ En todo caso relevantes los comentarios al respecto de Antonio Creus Carreras y Olivia Amador Peñate, «Procedimiento administrativo ante la Comisión Europea y control jurisdiccional del TJCE», op. cit., pp. 758-760.

${ }^{16}$ Así lo cree Mark Furse, Competition law of the EC and UK, New York, Oxford University Press, 2006, p. 90, quien sigue una senda similar a la planteada en Christopher BELLAMY, Graham ChiLd y Enric PICAÑol, Derecho de la competencia en el mercado común, op. cit., p. 680. También son relevantes los fundamentos al respecto que se hallan en los comentarios del abogado general F. G. Jacobs en razón de la Sentencia del Tribunal de Justicia de las Comunidades Europeas, Sala Quinta, de 19 de mayo de 1994, asunto C-36/92 P, Samenwerkende Elektriciteits-Produktiebedrijuen NV (SEP) vs. la Comisión de las Comunidades europeas (en lo sucesivo SEP vs. la Comisión), texto disponible para consulta en bttp://eur-lex. europa.eu/LexUriServ/LexUriServ.do?uri=CELEX:61992J0036:ES:pdf.

17 Algún sector de la doctrina cree que el examen es apropiado, aunque explican que difícilmente del mismo se obtengan respuestas claras acerca de la relevancia que tendrá la información a recolectar en la inspección en el descubrimiento de una infracción a las normas de libre competencia, ya que lo más difícil es decidir que una información en específico no es necesaria cuando puede ser indispensable para evidenciar la transgresión. Por lo que conceptúan que la noción de relevancia de la inspección como tal y de la información a obtener debe ser «somera» y no total. Vid. Valentine KORAH, An introductory guide to EC Law and practice, op. cit., p. 260. 
De tal manera que, si la inspección se basa en una simple autorización, los oficiales de la Comisión o las personas autorizadas por ella para llevar a cabo la diligencia deberán estar en posesión de dicho documento en el momento en el cual pretendan dar inicio a la misma; debiendo estar anexos a dicho escrito, de forma imperativa, el objeto y propósitos de la investigación, así como las sanciones que pueden serle impuestas a la empresa o asociación de empresas en aquellos casos en los cuales, de forma intencionada o negligente, aporten incompleta la documentación requerida, o cuando, en el marco de las preguntas que los oficiales de la Comisión están facultados para hacer a cualquiera de las personas presentes en el emplazamiento empresarial a título de empleados, se intente engañar aportando información o respuestas incorrectas, inexactas o similares, sin rectificar en el tiempo límite establecido para ello, de conformidad al letra $e$ ) del núm. 2 del art. 20 del Reglamento 1/2003 ${ }^{18}$.

Lo que implica entonces que, si bien las empresas o asociaciones de empresas pueden desmarcarse de la solicitud simple y negarse a someterse a la inspección fruto de este tipo de mandato ${ }^{19}$, dicha posibilidad no supone que cuando acepten la realización de la diligencia estén exentas de que les sea impuesta una multa en las eventualidades descritas en el párrafo anterior, conforme al art. 23 del Reglamento, de hasta el 1 por 100 del volumen de negocios total en el ejercicio económico precedente.

Aceptando que, de ser tomada la decisión de someterse a la inspección $^{20}$, la empresa no sólo debe permitir el acceso de los oficiales al lugar y a

${ }^{18}$ Las preguntas que bajo la vigencia del Reglamento 17/1962 estaban capacitados a realizar los oficiales de la Comisión a los empleados de la inspeccionada en cualquier caso, fuese la inspección en virtud de un mandamiento simple o una decisión, podían ser explicaciones acerca de referencias, términos, archivos, etc., pero nunca un interrogatorio general. Siendo una restricción que el Reglamento 1/2003 expandió, generando un poder mayor para pedir explicaciones sobre hechos y documentos con relación al asunto central y propósito de la diligencia. Vid. Alison Jones y Brenda Sufrin, EC Competition Law. Text, Cases and Materials, op. cit., pp. 1162 y 1163.

19 En términos similares a la posibilidad que tienen estas mismas de abstenerse de aportar la documentación que le es requerida por la Comisión por vía simple. Lo cual implica tomar la decisión de no someterse a la diligencia hasta cuando no sea una decisión en firme, o de someterse, bajo la premisa de que en este último caso deberá afrontar las consecuencias fruto de su decisión. Vid. Juan Manuel FernÁndez López, «Los Juzgados de lo Mercantil ante el Derecho comunitario de la competencia», Anuario de la Competencia, núm. 1 (2003), pp. 170 y 171.

${ }^{20}$ Decisión de cooperación que es entendida por los agentes investigados como un medio para comprobar su buena voluntad en el proceso, así como para llevar el mismo por un camino de anuencia y no de disputa, pues está más que interiorizado el paso futuro que conlleva negarse a colaborar con la Comisión tras una autorización simple, como es el retorno de los oficiales con una decisión en firme, que para expedirse se nutre del indicio que 
los archivos físicos o telemáticos donde puede estar depositada la información buscada por la Comisión, sino que igualmente debe asistir y colaborar con quienes realicen la diligencia en el encuentro de dicho material ${ }^{21}$, tal y como está obligada a hacerlo en el caso en que la inspección estuviese basada en una decisión ${ }^{22}$. Exigiéndosele igualmente el cumplir con la inspección de forma íntegra, hasta el final, pues no está capacitada para terminarla unilateralmente aduciendo que es resultado de una simple autorización; más allá de que durante la inspección descubra que su posición es comprometida tras la búsqueda emprendida por la autoridad comunitaria ${ }^{23}$.

El caso es distinto cuando la inspección está basada en una decisión, pues esta última, en adición a las sanciones que pueden ser impuestas cuando la diligencia es resultado de una autorización simple, debe contener una explicación acerca de las consecuencias pecuniarias que conlleva incumplir la misma. A saber, la Comisión está capacitada, conforme a las letras $c$ ) y d) del núm. 1 del art. 23 del Reglamento, a imponer multas del mismo valor cuando la «inspeccionada» rehúse someterse a la diligencia ${ }^{24}$.

puede significar el rechazo a someterse con el simple mandamiento inicial (aunque algunos dicen que la Comisión debe prevenirse de actuar en dicho sentido, pues que la empresa se resista a la inspección cuando es fruto de un mandamiento simple no siempre significa que haya algo que esconder). Vid. Valentine KoraH, An introductory guide to EC Law and practice, op. cit., p. 263. Al respecto, la Sentencia del Tribunal de Justicia de las Comunidades Europeas, Sala Quinta, de 24 de junio de 1986, asunto 53/85, AKZO Chemie BV vs. la Comisión de las Comunidades Europeas, texto disponible para consulta en http://eur-lex.europa. eu/LexUriServ/LexUriServ.do?uri=CELEX:61985J0053:ES:pdf.

${ }^{21}$ Pues incluso es la forma idónea para, de haber error en la interpretación de la situación por parte de la Comisión, poner de manifiesto la evidencia que contradiga el parecer de la autoridad comunitaria; demostrar, o por lo menos sugerir, cuáles son las correctas circunstancias que rodean las dudas de la Comisión, etc. Erigiéndose como indispensable que la iniciativa dentro de la diligencia esté en la empresa o asociación de empresas investigada, incluso si la inspección no ha sido anunciada. Vid. Valentine KoRAH, An introductory guide to EC Law and practice, op. cit., p. 264.

${ }^{22}$ Como así puede verse en la sentencia unificadora que acogió esta motivación inmersa en otro grupo de fallos previos bajo la vigencia del Reglamento 17/1962 del Tribunal de Justicia de las Comunidades Europeas, de 29 de junio de 2006, asunto C-301/04 P, La Comisión de las Comunidades Europeas vs. SGL Carbon AG (en lo sucesivo La Comisión de las Comunidades Europeas vs. SGL Carbón AG y otros), texto disponible para consulta en bttp://eur-lex.europa.eu/LexUriServ/LexUriServ.do? uri=CELEX:\%2062004J0301:ES:pdf, en concreto su apartado 40; siendo también relevante el fallo Orkem, en su apartado 27, y la Decisión de la Comisión 80/334/CEE, de 20 de diciembre de 1979, por la que se impuso una multa en razón del art. 15 del Reglamento núm. 17 a la empresa Fabbrica Pisana, disponible de forma auténtica sólo en italiano en http://eur-lex.europa.eu/LexUriServ/LexUriServ. do? uri=CELEX:31980D0334:IT:HTML. Nombrada por Mark FuRSE, Competition law of the EC and UK, op. cit., p. 92.

${ }^{23}$ Valentine KORAH, An introductory guide to EC Law and practice, op. cit., p. 263.

${ }^{24}$ Así como cuando decline responder preguntas que se le realicen en el curso de la 
A lo que debe añadirse que bajo la letra $e$ ) del núm. 1 del art. 24, la Comisión podrá también imponer multas del 5 por 100 del volumen de negocios medio diario del ejercicio social anterior por cada día de retraso en el cumplimiento de la decisión ${ }^{25}$, o lo que es lo mismo, por cada día que se rehúse o ponga trabas en el cumplimiento del mandamiento de la autoridad comunitaria.

Así como hay mayor rigidez en materia de multas en la inspección por decisión, igualmente la hay en lo referente a los mecanismos de coerción excepcionales que puede poner en marcha la Comisión cuando hay una negativa de la empresa a cumplir con el mandato de la Comisión, tal como demandar la colaboración del Estado miembro de la Comunidad Europea para que éste le proporcione fuerzas de seguridad, públicas o de policía en aquellos casos que lo ameriten ${ }^{26}$ y lo hagan necesario con el objetivo de permitir que la decisión de la Comisión pueda tener un asidero práctico ${ }^{27}$.

El núm. 6 del art. 20 del Reglamento 1/2003 aporta esta posibilidad, que a la par es desarrollada por los núms. 7 y 8 , donde se otorga claridad acerca de la importancia que tiene en este tipo de colaboración prestada por los Estados miembros el darle cumplimiento cabal a los requisitos

inspección o conteste a las mismas de forma engañosa, incompleta o inexacta, sin rectificar en el tiempo propuesto para ello. Vid. Alison Jones y Brenda Sufrin, EC Competition Law. Text, Cases and Materials, op. cit., p. 1163. En apreciación extensiva del art. 4, núm. 3, del Reglamento 773/2004, en el cual se expone que la inspeccionada podrá rectificar en el tiempo que se le otorgue para ello; caso en el cual cualquier modificación adherida deberá ser incorporada al expediente por parte de la Comisión.

${ }^{25}$ Sobre el tema en desarrollo, Wouter P. J. WILS, Efficiency and European antitrust enforcement, Portland, Hart Publishing, 2008, p. 4, quien acota que el Reglamento 17/1972 establecía unos límites a las penalidades pecuniarias que imponía, siendo la multa máxima de 5.000 euros y de 1.000 euros por día para multas coercitivas como las actualmente inmersas en el art. 24 del Reglamento 1/2003. Todas ellas sanciones que, en opinión del autor enunciado, deben ser comparadas para definir la mayor conveniencia del sistema acerca del tema.

${ }^{26}$ La solución a dicha reticencia es aportada por el núm. 6 del art. 20 del Reglamento $1 / 2003$, el cual dice: «Cuando los agentes y demás personas acreditadas al efecto por la Comisión constaten que una empresa se opone a una inspección ordenada con arreglo al presente artículo, el Estado miembro interesado les prestará la asistencia necesaria, requiriendo si es preciso la acción de la policía o de una fuerza pública equivalente para permitirles realizar su misión de inspección». Sobre esta posibilidad, y acerca de la importancia del papel de las autoridades y las fuerzas de los países miembros para llevar a cabo diligencias que ayuden a descubrir falencias en la competencia del mercado común, Lorenzo Federico PACE, European Antitrust Law. Probibitions, Merger Control and Procedures, Cheltenham, Edward Elgar Publishing, 2007, p. 253. Así como también el aporte que en este mismo texto se hizo al respecto en la nota al pie de p. 156.

${ }_{27}$ Un desarrollo especial sobre la asistencia de los Estados miembros en estas situaciones en Alison Jones y Brenda Sufrin, EC Competition Law. Text, Cases and Materials, op. cit., pp. 1163 y 1164. 
impuestos por la normativa interna; que en caso de requerir mandamiento judicial para que se haga efectiva dicha asistencia de las fuerzas públicas, deberá ser solicitada por la Comisión y puesta en consideración de un juez nacional, quien en su examen deberá constatar que:

- la decisión de la Comisión por la cual se ordena la inspección es auténtica, y

- las medidas coercitivas previstas no son excesivas ni arbitrarias conforme al asunto objeto de la investigación ${ }^{28}$.

Para motivar suficientemente su respuesta, el juez estará capacitado para solicitar información a la Comisión y formular las preguntas que estime pertinentes a aquella autoridad, e incapacitado para requerir toda la información que se encuentre sobre el asunto en los archivos de la Comisión y para poner en tela de juicio la necesidad de la diligencia ${ }^{29}$.

La empresa o asociación de empresas inspeccionada en razón de una decisión cuenta a la par con mecanismos de oposición distintos a los «físicos» o «materiales», que puede poner en marcha para impedir la realización de la diligencia ${ }^{30}$ o para, accediendo a la inspección, imposibilitar el

${ }^{28}$ Acerca de esta labor cooperativa que lleva a cabo un juez o Tribunal Nacional, así como de algunas de aquellas que se pondrán de manifiesto en detalle en este mismo trabajo al analizar los instrumentos de colaboración con que cuentan los enforcers privados para complementar la labor de los públicos, vid. Richard WAINWRIGHT, «Application of EC competition rules by national courts», artículo presentado para la conferencia «Antitrust reform in Europe: A year in practice», organizada de forma conjunta por el Colegio de Abogados Internacional y la Comisión Europea, Bruselas, 9-11 de marzo de 2005. El documento está disponible para consulta en lengua original en http://www.int-bar.org/images/downloads/ Richard\%20Wainwright\%20-\%20Paper.pdf.

${ }^{29}$ Sobre ello, los comentarios de la Sentencia del Tribunal de Justicia de las Comunidades Europeas de 22 de octubre de 2002, asunto C-94/2000, Roquette Frères SA vs. directeur général de la concurrence, de la consommation et de la répression des fraudes y la Comisión de las Comunidades Europeas (en lo sucesivo Roquette Frères). El documento está disponible para consulta en http://eur-lex.europa.eu/LexUriServ/LexUriServ. do? uri=CELEX:62000J0094:ES:pdf. En concreto su apartado 39, en el cual se lee: «Procede recordar, con carácter preliminar, que de la jurisprudencia del Tribunal de Justicia se desprende que el órgano jurisdiccional nacional competente, al realizar el examen, no puede sustituir, por la suya propia, la apreciación de la Comisión acerca del carácter necesario de las verificaciones ordenadas, ya que las valoraciones de hecho y de Derecho de la Comisión sólo están sometidas al control de legalidad de los órganos jurisdiccionales comunitarios». Donde a la par se recuerda la Sentencia Hoechst AG vs. la Comisión de las Comunidades Europeas, que en su apartado 35 establece un parámetro en el mismo sentido. Sobre el fallo y la posición del juez nacional en estos casos desde la óptica española, Julio PASCUAL Y VICENTE, «La nueva política comunitaria europea de control de conductas y su repercusión en España», Anuario de la Competencia, núm. 1 (2003), p. 141.

${ }^{30}$ Como parte de la revisión que puede realizar el Tribunal de Justicia de las Comuni- 
acceso de la Comisión a ciertos documentos cuando crea que dicha autoridad no tiene poder para apropiarse de ellos. Debiendo en ambos casos poner en consideración del Tribunal de Primera Instancia su percepción al respecto, pues en ningún caso la empresa está capacitada para decidir sobre dichos aspectos unilateralmente ${ }^{31}$.

Si bien implican niveles de compromiso distintos para las empresas o asociaciones de empresas, queda claro que tanto la inspección que se basa en una decisión como aquella que se basa en un mandato simple encuentran un punto conexo en el cual su desarrollo es equivalente cuando, en razón de la última, la «inspeccionada» accede a la realización de la diligencia, ya que en dicho momento el grado de implicación que se genera es idéntico al de la inspección por decisión y conlleva que el desarrollo de ambas diligencias sea análogo ${ }^{32}$.

dades Europeas de la decisión de la Comisión que ha sido recurrida. Posibilidad que, merced al núm. 4 del art. 20 del Reglamento 1/2003, debe estar incluida en la decisión misma y puesta en conocimiento de la empresa o asociación de empresas investigada.

${ }^{31}$ Un fallo de gran importancia acerca de la inspección basada en una decisión, que incluye en sus hechos un compendio de los elementos de contradicción de las empresas a la diligencia, así como de las actuaciones de los distintos enforcers en busca de darle cumplimiento al mandamiento de la Comisión, es el previamente enunciado en el presente trabajo (Hoechst A. G. vs. la Comisión), el cual nació de una sospecha de la Comisión acerca de la existencia de un acuerdo entre algunos proveedores y productores de polietileno y PVC que generó la adopción, el 15 de enero de 1987, de una decisión que ordenaba, en virtud del art. 14 del Reglamento núm. 17, una verificación al interior de la empresa Hoechst, que se intentó poner en marcha el 20 de enero, pero que se encontró con la negativa de la empresa, que alegaba que no permitía el registro por ser ilegal y por un compendio de razones que pretendían fueran puestas por escrito por los oficiales. Situación que se volvió a suscitar los días 22 y 23 de enero con el mismo resultado, generando una reacción de la Comisión que comunicó a la empresa que sería sancionada, como efectivamente lo hizo por medio de una decisión el día 3 de febrero. A la par, la Comisión solicitó asistencia de la Bundeskartellamt (Oficina Federal de Cárteles en Alemania) en virtud de los núms. 4 y 5 del art. 14 del Reglamento enunciado, quien a su vez buscó que la Amtsgerich, como Tribunal competente, expidiera una orden de registro, que esta última decidió no conceder el día 12 de febrero basándose en que no había hechos previos que justificaran la sospecha de existencia del cártel. Hoechst, a su vez, recurrió ante el Tribunal de Justicia tanto la decisión que ordenaba la verificación, como aquella que imponía la multa, no prosperando su solicitud. Suscitándose el otorgamiento que el 31 de marzo realizó la Amtsgerich de la orden de registro que, tras la negativa inicial de esta última, la Bundeskartellamt solicitó ahora en nombre de la Comisión y que generó que la diligencia se llevara a cabo los días 2 y 3 de abril, con una posterior decisión el día 26 de mayo en la cual la Comisión establecía los parámetros finales de la sanción; que no está de más decir también fueron objeto de acciones de Hoechst ante el Tribunal de Justicia por considerar que debían ser anuladas a la par con las decisiones de 15 de enero y de 3 de febrero.

32 En ambos casos, al momento de presentarse en el establecimiento o sede donde se llevará la inspección, los oficiales de la Comisión o las personas autorizadas por ella para la puesta en marcha de la misma deberán presentar un memorandum en el cual estén consig- 
Sea cual sea la modalidad elegida por la Comisión, ya en el curso propio de la pesquisa es importante que la empresa mantenga una actitud proactiva, que inicia con la disposición de un «comité» que se encargue de asistir a los inspectores de la Comisión en todo momento, el cual, se entiende, debe incluir en cualquier caso a un abogado y a un directivo con un largo historial de servicios dentro de la empresa, así como a un grupo de secretarias que, en el mismo número que los inspectores, estén dejando constancia documental, telemática o similar de todos los pasos que éstos den; de cuáles son los lugares y el material al que tienen acceso; qué documentos solicitan ${ }^{33}$; las respuestas que la empresa dé sobre los mismos: aportándolos $^{34}$ o rehusándose a suministrarlos, especificando las razones de dicha postura; registrando igualmente cada pregunta que formulen los oficiales al personal, y, en fin, todo lo que permita balancear la posición informativa de la empresa acerca de la inspección frente a la Comisión, quien normalmente no permite el acceso futuro de las investigadas al expediente donde se incluyen las anotaciones acerca de la diligencia.

La disposición de este grupo de personas, que a la par deben tener sustitutos ante imprevistos que se pueden suscitar, permite que la inspección y el proceso de investigación en general tengan una transparencia mayor y que las labores de colaboración y asistencia a la Comisión, así como de contradicción de las empresas, sean más efectivas, posibilitando que, por ejemplo, el abogado de la empresa valore los instrumentos jurídicos que empoderan a los oficiales de la Comisión ${ }^{35}$, o que objete, cuando

nados los derechos de la inspeccionada a contar en la diligencia con la asistencia de su representante legal, lo cual en ningún caso debe significar que la inspección sea retrasada. Vid. Valentine KoraH, An introductory guide to EC Law and practice, op. cit., p. 263.

33 Sobre los cuales merece resaltar que los inspectores de la Comisión o las personas facultadas por ella para realizar la diligencia no están capacitados para extraer copias completas de los discos duros de los ordenadores de la inspeccionada, debiendo en todo caso solicitar siempre documentos individuales por su nombre, que, de estar en formato electrónico, también podrán ser requeridos por aquéllos para guardar constancia de ellos en los expedientes de la Comisión, pero siempre de forma puntual y no total.

${ }^{34}$ El seguimiento continuo a los oficiales de la Comisión en el emplazamiento inspeccionado permite, a la par, dejar un registro de los documentos específicos que la Comisión tendrá a su disposición como evidencia, permitiendo a la inspeccionada contar con mayor conocimiento acerca del propósito de la autoridad y tener un margen de maniobra importante, en el cual incluso puede enviar a la Comisión explicaciones acerca del material en su poder que pueda ser interpretado como sospechoso al no estar en contexto.

35 No sólo para determinar, en el momento inicial en el cual los oficiales de la Comisión se presentan en el emplazamiento donde van a llevar a cabo la inspección, si los documentos que presentan les dan el suficiente poder para llevar a cabo la diligencia, sino también para, dentro del desarrollo de la misma, diagnosticar si el mandamiento o la decisión son insuficientes; caso en el cual deberá informar a su representado cuáles son las consecuencias de 
sea el caso, la formulación de preguntas sugestivas, complejas, engañosas o similares, como también que no se esté otorgando suficiente tiempo a los «entrevistados» para que motiven su respuesta o revisen el material necesario donde se incluye la información de lo preguntado.

$\mathrm{Al}$ parecer, además de la predisposición y receptividad de la «inspeccionada» en el desarrollo de la diligencia, existe un punto de encuentro claro entre las modalidades de inspección fruto de una autorización simple, o de una decisión, en lo referente a la obligada participación de las autoridades nacionales de la competencia en este tipo de diligencias, aunque, eso sí, con matices en el nivel de implicación, que resulta ser más intenso en el caso de la última.

Los núms. 3 y 4 del art. 20 del Reglamento 1/2003 establecen una obligación en ambos casos de involucrar a las autoridades nacionales de la competencia del país donde se realizará la inspección, de la cual se infiere que, cuando la diligencia sea en ejercicio de los poderes de la Comisión por medio de la presentación de un mandamiento escrito simple, aquélla solamente deberá advertir con antelación de la misión a la autoridad de competencia del territorio, mientras que, cuando es por decisión, antes de la toma de la misma la Comisión deberá consultarle sobre ella a la autoridad del país donde se va a llevar a cabo la diligencia.

Los apartados mencionados dejan en el aire un aspecto de importancia, como es la capacidad que las autoridades nacionales de la competencia tienen para oponerse a la inspección en los casos en los cuales esté soportada en una autorización simple o en una decisión. El carácter etéreo al respecto genera dudas razonables que indican que, tal vez, las autoridades nacionales tendrán más que decir y más capacidad de maniobra, incluso para oponerse, cuando la inspección sea ordenada por una decisión, pues en todo caso ser consultado no es lo mismo que ser notificado y, por tanto, debe generar efectos diversos que, no está de más decir, no están claramente delimitados y están capacitados para entorpecer la labor dual de los Enforcement Bodies ${ }^{36}$ de las normas de libre competencia comunitarias.

dicha insuficiencia y cuáles son los efectos que se generan en el curso de la diligencia, tales como poder negarse a proveer ciertos documentos por ser material privilegiado o irrelevante, etc. Vid. Valentine KoraH, An introductory guide to EC Law and practice, op. cit., p. 263.

36 Silke Brammer, Cooperation Between National Competition Agencies in the Enforcement of EC Competition Law, Oxford-Portland, Hart Publishing, 2009, p. 1. El autor critica a quienes interpretan la palabra bodies como cuerpo administrativo, y expone que es ésta la forma correcta de enunciar a todos aquellos cuerpos, colegiados o no, con poder para administrar justicia en materia de competencia o en posición de hacerlo. A saber, la Comisión 
A pesar de algunas imprecisiones como las enunciadas, referentes al tránsito de colaboración entre las autoridades nacionales de la competencia y la Comisión, el Reglamento 1/2003 parece dejar claro, en todo a lo que la inspección se refiere, que no puede ser desaprovechada la cooperación que las primeras pueden prestar a la autoridad comunitaria en estos $\operatorname{casos}^{37}$, pues en no pocas circunstancias son quienes pueden ser autorizadas para acudir a las diligencias cuando se estén llevando misiones simultáneas en varios Estados miembros en busca de descubrir un mismo cártel, o simplemente, quienes por su conocimiento del territorio, las costumbres, la lengua, etcétera, en mejor posición se encuentran para asistir a los oficiales de la Comisión en todo momento en la práctica de la inspección ${ }^{38}$.

La realización efectiva de la inspección, una vez superadas todas las cuestiones enunciadas, ha generado intensos debates alrededor de otros aspectos $^{39}$ que, a la par, han envuelto la facultad de la Comisión para solicitar información, los cuales, si bien cuentan con sustento jurisprudencial y sendas doctrinas que los aclaran, aun adolecen de imprecisión y deben

Europea, las autoridades administrativas nacionales de competencia, autonómicas, los jueces y los tribunales arbitrales.

37 Plantea los beneficios de la compenetración de las autoridades en este caso específico y enuncia las eventualidades que se pueden suscitar, que hacen necesaria la participación de los agentes de la autoridad nacional de competencia del país del territorio de la diligencia. Vid. Valentine KoraH, An introductory guide to EC Law and practice, op. cit., p. 262.

${ }^{38}$ De la lectura del núm. 5 del art. 20 del Reglamento se extrae que las autoridades nacionales de competencia, por medio de sus agentes, a la par del conocimiento enunciado acerca de la diligencia y de los aspectos hasta aquí expuestos, en razón de los cuales acompaña la realización de la inspección, deben estar en disponibilidad de prestar la asistencia que les sea requerida y de colaborar como les sea solicitado por la Comisión y por la autoridad misma a la cual representan, en búsqueda de la ejecución de la diligencia, para lo cual le serán otorgados los poderes del núm. 2 del mismo artículo.

${ }^{39}$ Entre los cuales se desea resaltar, como uno más de aquellos argumentos aducidos por las empresas para abstraerse de la obligación de darle cumplimiento a la decisión de inspección, el de la efectiva puesta en marcha de la diligencia; donde llama la atención la Sentencia del Tribunal de Justicia de las Comunidades Europeas de 26 de junio de 1980, asunto 136/79, National Panasonic (UK) limited vs. la Comisión de las Comunidades Europeas, disponible para consulta en http://eur-lex.europa.eu/LexUriServ/LexUriServ. do? uri=CELEX:61979J0136:ES:pdf, donde una empresa tomó la decisión de combatir las vías de verificación y de puesta en marcha de la diligencia de la Comisión alegando imposibilidad para controvertir la decisión y falta de suficientes precedentes de inspección, con una solicitud clara de que fueran destruidos o retornados la totalidad de documentos extraídos en la verificación. A la postre terminó con la desestimación de los argumentos de National Panasonic y con el refuerzo de la Comisión por entenderse que se habían cumplido todos los requisitos de ley y que existían parámetros que otorgaban suficientes garantías a la empresa y a cualquiera en su posición. Para ahondar acerca de la reseña de este fallo y sus conclusiones sobre lo que aquí se expuso en resumen Mark FurSE, Competition law of the EC and UK, op. cit., p. 94. 
ser retocados en busca de una delimitación más propia de la importancia de los poderes mencionados ${ }^{40}$.

Los debates son generados por la ambigüedad acerca del secreto profesional que ampara a cierto material documental, así como por la autoincriminación a la cual se empuja a los investigados con una solicitud de información o con una inspección en la cual se formulan preguntas a su personal ${ }^{41}$. Llama la atención, por ejemplo, que cuando la Comisión pone en funcionamiento alguno de estos dos poderes enunciados por medio de una decisión, incluso guardar silencio en busca de no inculparse a sí mismo puede ser motivo de sanción ${ }^{42}$.

El poder casi «hegemónico» que se deja entrever en ciertos aspectos de las atribuciones de inspección y de solicitud de información de la Comisión es en alguna proporción incoherente, pues si bien, por un lado, el Reglamento ha intentado otorgar claridad total acerca de los límites que tienen los oficiales de la Comisión para llevar a cabo las inspecciones con el ánimo de delimitar sus atribuciones y a la par evitar comportamientos arbitrarios que perjudiquen la confianza de las empresas, por el otro, inci-

${ }^{40}$ Esta opinión se extrae de algún sector de la doctrina que desarrolla el poder en estudio, tales como Antonio Javier AdRIÁn ARnÁIZ y Jesús QUIJANo GONZÁLEZ, «Procedimiento de aplicación de las reglas sobre competencia de los arts. 81 y 82 del Tratado de la Comunidad Europea», en Luis Antonio Velasco San Pedro (coord.), Derecho europeo de la competencia: antitrust e intervenciones públicas, Valladolid, Lex Nova, 2005, pp. 410 y ss.

${ }^{41}$ Entiende que, a pesar de que la línea entre el poder de preguntar a las personas naturales durante la inspección y la autoincriminación sea muy delgada, esta última no se configura en la diligencia, aunque, valga decir, no expone de forma suficiente las razones que fundamentan su posición. Vid. Valentine KoraH, An introductory guide to EC Law and practice, op. cit., p. 260.

${ }_{42}$ Este caso le parece de gran extrañeza a algún sector de la doctrina, que interpreta que hay desprotección de la empresa o asociación de empresas en la inspección en lo referente a las preguntas que están capacitados los oficiales para hacerle a cualquier miembro del personal de éstas durante la diligencia. Dichos comentarios son puntuales y de una claridad total en Alison Jones y Brenda Sufrin, EC Competition Law. Text, Cases and Materials, op. cit., p. 1173, quienes interpretan que es en todo caso problemático para las empresas que la Comisión pueda dirigir sus preguntas a personas naturales, entre las cuales pueden estar empleados descontentos; más aún cuando no hay un derecho de la empresa a acceder a una copia de la entrevista. A lo que añaden que en respuesta a esa «indefensión» sobre el tema no parece haber razón por la cual una empresa no pueda instruir a sus empleados a no aceptar invitaciones a entrevistas entre tanto no se garantice un asesoramiento legal y no se den unas garantías que estén planteadas en términos de igualdad. Como contraste a lo expuesto por la doctrina nombrada, los parámetros de la Comisión en el asunto Fabbrica Pisana, de donde se extrae que, si bien los inspectores están capacitados para hacer preguntas al personal, es labor de la empresa presentar a las personas que, en su concepto, se encuentren en mejor posición para responder a las preguntas, pues la Comisión no es quien debe evaluar las competencias o conocimientos de los empleados. 
ta a los investigados a que acepten sus responsabilidades por medio de sus respuestas o por medio de la documentación que en el curso de la inspección les es requerida ${ }^{43}$.

Siendo entonces de tanta importancia los conflictos que se generan entre varios de los poderes de investigación de la Comisión con el secreto profesional y con el derecho a no autoincriminarse, se hace latente, por la capacidad que tienen estos últimos de influenciar la pesquisa llevada a cabo por la Comisión y por la extensión misma que requiere su exposición, la necesidad de desarrollarlos en profundidad de forma individual, para, de esta manera, otorgar claridad acerca del estado actual de la cuestión y del margen de maniobra con el cual cuentan tanto la Comisión como los investigados en lo que a ellos se refiere, así como para entender de forma completa cuál es la incidencia que tienen en la práctica de la inspección.

Antes debemos resaltar los aspectos más esenciales de una innovación de gran importancia adherida al Reglamento 1/2003 como es la posibilidad de llevar a cabo inspecciones en «otros locales» diferentes de los empresariales y/o comerciales, la cual amerita igualmente un desarrollo particular por ser un tema controvertido que ha generado amplios debates, pues si bien se encuentra soportado como una dilatación lógica de la atribución de realizar inspecciones, tiene algunos elementos que le diferencian ampliamente de la diligencia llevada a cabo en un emplazamiento empresarial no sólo referentes a los requisitos que debe cumplir para poder ser puesta en marcha, sino también en lo que a la práctica misma de la inspec-

${ }^{43}$ El tema de la autoincriminación en relación a la solicitud de información y también respecto de la atribución de llevar a cabo inspecciones es desarrollado por un sector de la doctrina que interpreta que un grupo de fallos son los de más relevancia sobre el asunto, los cuales han coincidido en el tiempo al acotar que debe estar permitido a la empresa o asociación de empresas guardar silencio respecto de ciertas preguntas de la Comisión cuando responderlas pueda generar una autoinculpación (máxime cuando las preguntas formuladas por la Comisión vayan más allá de aquello que requieren para darle solución a una investigación o, en términos generales, de lo que están autorizados para preguntar); lo que en ningún caso debe hacerse extensivo a la aportación del material documental que le es requerido en una inspección o sin la existencia de ella, pues en dichos casos el agente investigado siempre deberá colaborar entregándolo, incluso si dichos documentos llevan inmersos información que le involucra con la infracción. Cfr. los fallos en relación a Orkem (en especial sus apartados 33 a 36) y Solvay previamente reseñados; la Sentencia del Tribunal de Primera Instancia, Sala Primera ampliada, de 20 de febrero de 2001, asunto T-112/98, MannesmannröhrenWerke AG vs. la Comisión de las Comunidades Europeas, texto disponible para consulta en http://eur-lex.europa.eu/LexUriServ/LexUriServ.do? uri=CELEX:61998A0112:ES:pdf, apartados 65 a 67; así como la sentencia La Comisión de las Comunidades Europeas vs. SGL Carbón $A G$ y otros, apartados 33 a 51. Sobre los parámetros descritos vid. Richard WHISH, Competition Law, op. cit., p. 267. 
ción se refiere, ya que cuenta con restricciones puntuales que merecen ser expuestas de forma especial.

A continuación entonces una presentación de los aspectos enunciados en los dos párrafos precedentes, no sin antes manifestar, en consonancia con las atribuciones hasta este punto descritas, que la inspección es, posiblemente, el poder más eficaz con el cual cuenta la Comisión para destruir conductas perjudiciales para la competencia comunitaria, pues permite el desarrollo in situ de la atribución, accediendo al material que la investigación previa, en uso de los demás poderes ${ }^{44}$, ha arrojado como pertinente ${ }^{45}$. Todo ello como manifestación de los recursos extraordinarios con los que cuenta la autoridad comunitaria, que le posicionan en un nivel de privilegio frente a los otros Enforcement Bodies.

\section{LA PROLONGACIÓN DE LA FACULTAD DE INSPECCIÓN}

El art. 21 del Reglamento 1/2003 plantea un poder que, como ya se enunció en el apartado anterior, no estaba contenido en el Reglamento $17 / 1962$ en lo que a los «poderes de verificación» se refiere, y que resulta ser una innovación que amplía los poderes de inspección de la Comisión ${ }^{46}$ en busca de contener ciertos comportamientos comunes de los agentes por medio del otorgamiento de una herramienta más eficaz y más contundente en cabeza de la autoridad comunitaria ${ }^{47}$.

El Reglamento mencionado pone de manifiesto desde el inicio, en concreto en su num. 26, la práctica más que común llevada a cabo por las empresas y por los empleados de mayor rango dentro de la misma como es la de almacenar los documentos con capacidad de arrojar luces acerca

44 A pesar de ser una situación común en la cual los poderes de la Comisión en materia de investigación se van concatenando en aras de llegar a una conclusión benéfica para la defensa de la competencia, no hay ningún precepto legal que plantee un procedimiento previo a la inspección que la Comisión deba seguir para poder llevar cabo la diligencia.

${ }^{45}$ Es de esta opinión, y en exposición de las particularidades de las atribuciones de la Comisión para llevar a cabo diligencias de inspección, Antonio CREUS CARRERAS y Olivia Amador Peñate, «Procedimiento administrativo ante la Comisión Europea y control jurisdiccional del TJCE», op. cit., pp. 763 y ss.

${ }^{46}$ Resalta en su texto la conmoción que generó la simple propuesta de la Comisión y la relevancia que está en capacidad de tener este poder en la obtención de un objetivo específico de la autoridad comunitaria, el cual es descubrir cárteles y conductas anticompetitivas. Vid. Valentine KoraH, An introductory guide to EC Law and practice, op. cit., p. 261.

${ }^{47}$ Pone de manifiesto esta circunstancia José Luis GIL IbáÑEZ, «La Comisión y la aplicación del Derecho comunitario de la competencia», op. cit., p. 125. 
de la existencia, funcionamiento o distintivos de un cártel en locales pri$\operatorname{vados}^{48}$. A lo que añade que, en respuesta a dicha conducta y en busca de que las diligencias de inspección sigan realizándose en términos de eficacia, a los agentes de la Comisión o a las personas facultadas por ésta para llevar a cabo la pesquisa se les debe permitir acceder a esos emplazamientos de carácter privado distintos a los propios de la empresa o asociación de empresas investigada ${ }^{49}$.

Dichos locales hacen referencia, en especial, a los hogares, vehículos o similares que pertenezcan a los directores, gerentes o estrechos colaboradores de la empresa, donde la Comisión, con el soporte de un indicio razonable, crea poder encontrar material documental acerca del objeto de la diligencia que esté en capacidad de servir de sustento probatorio de una transgresión a las normas de libre competencia ${ }^{50}$.

El núm. 1 del art. 21 del Reglamento 1/2003 otorga una amplitud importante acerca de quiénes pueden ser las personas en cuyos domicilios particulares podrán ser llevadas a cabo las inspecciones, dejando claro y posibilitando concluir que cualquier miembro de la empresa o asociación de empresas, sea cual sea el nivel del mismo, podrá ser objeto de la diligencia, siempre y cuando la Comisión tenga una señal clara que indique que ciertas pruebas se encuentran en su emplazamiento particular ${ }^{51}$.

${ }^{48}$ Esta realidad quedó retratada, en parte, gracias a la Decisión de la Comisión de 18 de julio de 2001, relativa al procedimiento de conformidad con el art. 81 del Tratado CE y el art. 53 del Acuerdo sobre el Espacio Económico Europeo, asuntos COMP.D.2 37.444, SAS/ Maersk Air, y COMP.D.2 37.386, SUN-Air vs. SAS y Maersk Air, texto disponible para consulta en bttp://eur-lex.europa.eu/LexUriServ/LexUriServ.do\% 20?uri=OJ:l:2001:265:0015:004 1:es:pdf, donde quedó claro que documentos importantes relativos a un pacto de reparto de mercado dirigido a impedir, restringir y falsear la competencia se guardaban en los hogares de los vinculados y no en el emplazamiento empresarial, como así puede verse en los apartados 7 y 123 de la mencionada, así como en el 89, de donde se sustrae el extracto que se considera de más relevancia: «[Un representante de Maersk Air] afirmó que había que destruir todo el material de los acuerdos sobre precios, acuerdos de reparto del mercado y similares antes de que nos fuéramos hoy. Había que llevar a casa cualquier cosa que se hubiera utilizado. También había que suprimir de los ordenadores cualquier material comprometedor».

49 Ante la más que común práctica de poner los documentos o el material que sirva para probar la infracción fuera del alcance de la Comisión, esta última debe contar con la oportunidad de llegar a ellos por medio de mecanismos como la inspección en detalle. Como así se concluye de la lectura de Mark FunSE, Competition law of the EC and UK, op. cit., p. 94.

50 Desarrollo de esta atribución como respuesta a una conducta común de los implicados en el núm. 40 de la Comunicación relativa a la cooperación entre la Comisión y los órganos jurisdiccionales de los Estados miembros para la aplicación de los arts. 85 y 86 del Tratado CEE del año 1993 (publicada en el Diario Oficial de la Unión Europea, núm. C 101/60, de 27 de abril de 2004).

${ }_{51}$ Como no podía ser de otra forma, al ser novedoso el poder conferido por el mencionado artículo a la autoridad comunitaria, la doctrina entró en un debate dirigido a deter- 
La inspección debe ser ordenada mediante una decisión, que antes de ser adoptada requiere de la consulta por parte de la Comisión a la autoridad nacional de la competencia del territorio donde se llevará a cabo la diligencia. En todos los casos, en el cuerpo de la decisión deberán estar consignados los mismos aspectos que le son requeridos cuando la diligencia se lleva a cabo en la sede empresarial ${ }^{52}$, no siendo requisito único a cumplir para poder poner en marcha de forma efectiva la diligencia, ya que, a la par, está supeditada a una participación de los jueces nacionales en términos similares a los planteados en el núm. 6 del art. 20, pero con ciertas particularidades excepcionales que al parecer han sido impuestas en razón de ciertos derechos que están involucrados con una decisión de este estilo.

La diferencia radica en que, en los casos contemplados en el art. 20, la autorización de un juez nacional sólo es requerida cuando la normativa nacional contempla dicha obligación, mientras que en lo descrito en el núm. 3 del art. 21 se establece que una decisión que implique la inspección en «otros locales» no puede ser ejecutada hasta tanto haya una autorización proferida por un órgano jurisdiccional competente del Estado de realización de la diligencia, quien, eso sí, y a pesar de haber más amplitud y frecuencia en la realización de dicha labor, deberá realizar un examen en términos similares a los del primer caso, verificando que:

- La decisión de la Comisión por la cual se ordena la inspección es auténtica.

- Las medidas coercitivas previstas no son excesivas ni arbitrarias ${ }^{53}$ conforme a la gravedad de la presunta transgresión y al grado de implicación de la empresa en la infracción.

minar con exactitud cuáles son los distintivos de las personas que pueden ser objeto de las inspecciones en desarrollo; planteándose la pregunta de si en dichas personas podían estar incluidos los abogados de las empresas. Cuestionamiento que, tras razonarlo, les llevó a concluir que, de ser reconocido el abogado como el representante legal de la empresa, dicha posibilidad no le sería aplicable. Vid. Lorenzo Federico PACE, European Antitrust Law. Probibitions, Merger Control and Procedures, op. cit., p. 255.

${ }_{52}$ Los cuales están consignados en el núm. 2 del art. 21 del Reglamento en los siguientes términos: «La decisión precisará el objeto y la finalidad de la inspección, indicará la fecha de su comienzo e informará sobre el derecho de recurso contra la decisión ante el Tribunal de Justicia de las Comunidades Europeas. La decisión expresará, en particular, en qué motivos se basa la sospecha de la Comisión con arreglo al apartado 1».

53 A pesar de ser un fallo suscitado bajo la vigencia del Reglamento 17/1962, el asunto Roquette Frères resulta ser de obligada lectura y análisis respecto de la posición de los jueces nacionales de los países miembros ante las autorizaciones para llevar a cabo las diligencias de inspección en lugares privados, toda vez que en su texto se sientan las bases que justifica- 
- Las mencionadas medidas son coherentes y proporcionadas con la importancia que tienen para el objeto de la investigación las pruebas que se pretenden encontrar, debiendo existir una probabilidad razonable de que el material objeto de la diligencia se encuentre en el lugar señalado para el cual se requiere la autorización ${ }^{54}$.

$\mathrm{Al}$ igual que en el caso en que se requiera su autorización para llevar a cabo la inspección en sede empresarial, el juez nacional no debe excederse en sus funciones, estando entonces imposibilitado para poner en tela de juicio la necesidad de llevar a cabo la diligencia o para requerir toda la información que consta en el expediente de la Comisión, ya que dicha labor sólo puede ser realizada por el Tribunal de Justicia ${ }^{55}$. Estando capacitado, eso sí, para, en busca de facilitar el cumplimiento de su labor, formular a la autoridad comunitaria las preguntas que estime pertinentes ${ }^{56}$.

La participación del Estado miembro en este tipo de inspección no se restringe al campo judicial y se ve nutrida por aspectos del art. 20 del Reglamento que le son igualmente aplicables en razón de la analogía que el núm. 4 del art. 21 dice debe existir en la aplicación de los núms. 5 y 6 de aquél.

Así las cosas, en virtud de dichos preceptos, en la inspección en «otros locales», al igual que en la diligencia en emplazamientos empresariales, los agentes de las autoridades nacionales de la competencia también deberán prestar asistencia cuando les sea requerida por la Comisión; caso en el cual serán empoderados en los mismos términos que los oficiales de la autoridad comunitaria, conforme al núm. 2 del art. 20.

ron la estructuración de los parámetros que con posterioridad fueron incluidos en el paquete de modernización, en concreto en sus apartados 6, 19, 27, 29 y 59.

54 El desarrollo de dichos aspectos en el asunto Roquette Frères, apartados 79, 80 y 99, así como las apreciaciones de la parte resolutiva.

${ }_{55}$ Lorenzo Federico PACE, European Antitrust Law. Probibitions, Merger Control and Procedures, op. cit., p. 256. La misma tónica doctrinal también en José Luis CONCEPCIÓN Rodríguez, Rafael Gimeno-Bayón Cobos y Luis Rodríguez VegA, «Coordinación entre los tribunales, la Comisión y las autoridades nacionales en la aplicación de los arts. 81 y 82 del TCE», Cuadernos de Derecho Judicial, núm. 17 (2004), p. 215.

${ }_{56}$ Para algunos autores, la extensión de los parámetros del examen realizado por los jueces nacionales en el caso de la inspección en otros locales con respecto a los otorgados en el art. 20 del Reglamento acerca de la inspección en los emplazamientos empresariales es acertada, toda vez que la razonabilidad del indicio y la valoración de la importancia de las pruebas a encontrar generan un mayor margen de maniobra a favor del juez, que tiene más motivos por los cuales requerir información de la Comisión para de tal forma motivar su decisión en consonancia con la sensibilidad de los aspectos que involucra la inspección en domicilios, vehículos o locales privados en general. Vid. Alison Jones y Brenda Sufrin, EC Competition Law. Text, Cases and Materials, op. cit., p. 1172. 
Lo que se une a la colaboración y a los mecanismos coercitivos que pueden ser provistos por los Estados miembros a la Comisión cuando esta última los solicite, poniendo a su disposición fuerzas de seguridad del Estado, públicas o similares, en aquellos casos en los se requieran para poder llevar a cabo este tipo de inspección, cuando esté siendo ejercida una oposición por parte de la persona titular del local a inspeccionar que impida la realización de la diligencia de inspección en el emplazamiento requerido ${ }^{57}$.

Otorgar instrumentos de cooperación como los descritos a favor de la Comisión, también en lo que a inspección de otros locales se refiere, no significa que haya una transposición completa de todos los fundamentos de la inspección del art. 20 a la inspección del art. 21, pues hay aspectos puntuales que generan divergencia entre ambas diligencias. La diferencia de más relevancia es aquella referente a las multas sancionadoras y a las multas coercitivas de los arts. 23 y 24 del Reglamento, las cuales no son aplicables a la inspección en otros locales, generando una imposibilidad de la Comisión a imponerlas en estos casos, incluso si se presentan eventualidades análogas; comportando un contraste especial que en todo caso debe ser tomado en cuenta.

Como también deben ser atendidas las facultades con las que cuentan los agentes en este tipo de diligencias; quienes en el curso de la inspección estarán capacitados para examinar cualquier registro que tenga relación con la empresa, sacar fotocopias de documentos o apartes de éstos, etcétera, y a su vez inhabilitados para colocar precintos en lugares o zonas específicas del local «particular» o en documentos que ahí encuentren, así como también para solicitar explicaciones ${ }^{58}$ en términos similares a los de la inspección del art. 20 del Reglamento.

Por ser una atribución aun en construcción y en razón de ser un poder que tiene contacto con aspectos especialmente sensibles, es previsible que sea ejercido de forma excepcional y sólo en ocasiones específicas en las que la Comisión crea conveniente ponerlo en marcha como último recurso, cuando entienda que recabar información relevante pasa por inspeccionar

57 Acerca de la aplicabilidad de los fundamentos de la inspección del art. 20 del Reglamento a la diligencia del art. 21 puede verse Wouter P. J. WiLs, Efficiency and European antitrust enforcement, op. cit., p. 6.

${ }^{58}$ Como así puede concluirse de la lectura del art. 21 al no encontrarse mención al respecto. Siendo ésta la opinión de Alison Jones y Brenda Sufrin, EC Competition Law. Text, Cases and Materials, op. cit., p. 1172, y de Wouter P. J. WiLs, Efficiency and European antitrust enforcement, op. cit., p. 6. 
locales privados de los responsables individuales de los cárteles, sobre los cuales tiene indicios de ser lugares de resguardo de dicho material ${ }^{59}$.

\section{EL SECRETO PROFESIONAL Y SU AGITADA RELACIÓN CON LAS FACULTADES DE INSPECCIÓN DE LA COMISIÓN}

Existe cierta distorsión y confusión alrededor del secreto profesional ${ }^{60}$ en aquello relacionado con la facultad de inspección que está empoderada para poner en marcha la Comisión en el marco de una pesquisa concurrencial; toda vez que, bajo el mismo postulado, la doctrina ha desarrollado dos aspectos conexos pero no idénticos ${ }^{61}$, como son (i) la posibilidad que en razón de este privilegio tienen las empresas de retener cierta documentación que esté amparada por el secreto, y (ii) la obligación que tiene la autoridad comunitaria de darle al material documental el uso específico por el que ha sido recabado ${ }^{62}$.

Ambas acepciones tienen un nivel de coherencia y pertinencia importante que les relaciona directamente con el título genérico, «secreto profesional», por lo que interpretar que no hay error en la doctrina al haber desarrollado bajo este mismo postulado las dos figuras no resulta descabellado, ya que las mismas exponen aspectos que son símiles.

Las semejanzas no convierten ambos postulados en uno solo, sino que ocasionan una obligada división interna que debe ser estructurada para diferenciarlos. Lo que a la postre genera sorpresa, toda vez que una parte importante de la doctrina comúnmente ha tomado la decisión

59 Un sector de la doctrina así lo interpreta, añadiendo que parece ser en todo caso correcto que la Comisión cuente con dicha posibilidad, pues achica el marco de actuación de los transgresores en potencia y de los infractores. Vid. Richard Whish, Competition Law, op. cit., p. 271.

${ }^{60}$ De forma general los comentarios de Mark Funse, Competition law of the EC and UK, op. cit., pp. 97 y 98; así como Valentine KoraH, An introductory guide to EC Law and practice, op. cit., pp. $265-268$.

${ }^{61}$ Ejemplo de ello y bajo el título «Legal Professional Privilege», en Richard WHISH, Competition Law, op. cit., p. 268; «Confidentiality», en Valentine KorAH, An introductory guide to EC Law and practice, op. cit., p. 265, y «Secrecy», en Mark FuRSE, Competition law of the EC and UK, op. cit., p. 97.

$62 \mathrm{Al}$ respecto se resalta la exposición que se hace sobre los mencionados temas en Ivo Van Bael y Jean-François Bellis, Competition Law of the European Community, Alphen aan den Rijn (Holanda), Kluwer Law International, 2010, pp. 1023-1033, donde los autores realizaron una división clara de ambos temas bajo los títulos: «Legal Privilege», «Use of Information purpose of the inquiry» $\mathrm{y}$ «Professional Secrecy», referidos en dicho orden a los puntos (i) e (ii) enunciados en el párrafo origen del presente pie de página. 
de decantarse por uno u otro, incluso dejando de lado alguno de ellos en su exposición.

En el presente apartado ambos aspectos serán unificados, pues se percibe una fuerte relación entre ellos, pero desarrollándolos de forma puntual resaltando sus particularidades, ya que se entiende que cuentan con suficientes distintivos que hacen necesaria su exposición.

\section{LA EXISTENCIA Y DESARROLLO DEL PRIVILEGIO}

Al respecto del secreto profesional que ampara ciertos documentos que eventualmente pueden ser solicitados por la Comisión como parte de una investigación llevada a cabo por ésta, ya sea en razón de la atribución de solicitar información del art. 18 o en el curso de una inspección de los arts. 20 y 21, cabe decir que los fundamentos que delimitaron dicha eventualidad fueron planteados en la Sentencia Australian Mining \& Smelting Europe Limited vs. la Comisión de las Comunidades Europeas (en lo sucesivo AM E S Europe Limited vs. la Comisión) ${ }^{63}$, en la cual no se proporcionaron a los agentes de la autoridad comunitaria algunos documentos requeridos en el curso de una inspección por entenderlos cubiertos por el legal privilege ${ }^{64}$.

El fallo mencionado, a pesar de haberse suscitado bajo la vigencia de otros instrumentos normativos y en una realidad diversa, incluye aspectos que incluso en la actualidad, y bajo el prisma del Reglamento $1 / 2003$, son aplicables, y que durante veintiocho años fueron la guía básica a seguir en lo que a protección documental amparada en el secreto profesional se refiere ${ }^{65}$.

${ }^{63}$ Sentencia del Tribunal de Justicia de las Comunidades Europeas de 18 de mayo de 1982, asunto 155/79, texto disponible para consulta en bttp://eur-lex.europa.eu/LexUriServ/ LexUriServ.do?uri=CELEX:61979J0155:ES:pdf.

${ }^{64}$ Con antelación al fallo mencionado también se suscitaron debates a su alrededor, sobre todo en razón de la evolución que sobre el tema se había dado en Estados Unidos, que a la par soportaba el cuestionamiento acerca del privilegio de secreto profesional no sólo en lo que hacía referencia a la defensa de la competencia. Así, por ejemplo, Stephen STEWARD y David Vaughan, «Does legal profesional privilege exist in the ECC?», Law Society Gazette, núm. 1207 (1975), p. 72; Maitre Xavier TANDEAU DE MARSAC, «Professional Privilege (confidentiality)», International Bar Journal, noviembre de 1976, p. 32, y D. EDWARD, «Confidentiality and privilege in the ECC context», National Law Journal, núm. 128 (1978), p. 1208.

${ }^{65} \mathrm{La}$ sentencia mencionada generó debates doctrinales de ahínco alrededor de cada uno de sus aspectos, los cuales pueden encontrarse, entre otros, en Theofanis CHRISTOFOROU, «Protection of legal privilege in ECC competition law: The imperfections of a case», 
Durante los años mencionados y hasta la actualidad, en ausencia total de normas que regulen este delicado aspecto, la sentencia enunciada fue una baza principal de consulta al respecto, pues sentó bases claras sobre aspectos puntuales gracias al enfoque que siguió al encauzarse en dos planteamientos específicos, como lo fueron: (i) delimitar la existencia de una doctrina de privilegio en el Derecho comunitario, y de existir, (ii) establecer los mecanismos idóneos que permitan determinar si un documento está amparado por dicho privilegio o no ${ }^{66}$.

Tras dejar clara la respuesta al cuestionamiento inicial, reconociendo que la confidencialidad de las comunicaciones entre los abogados y sus clientes es un derecho de nivel comunitario que no puede ser desconocido bajo ningún concepto por los miembros de la Comisión ${ }^{67}$, sostuvo que debían ser erigidos ciertos límites a dicho derecho ${ }^{68}$, como así lo hizo, manifestando que los representantes a los cuales hace referencia este derecho deben ser de un país comunitario ${ }^{69}$ y que no pueden, bajo ninguna circunstancia, ser abogados In House, pues al no estar sujetos estos últimos

Fordham International Law Journal, vol. 9, núm. 1 (1985), pp. 1-62; así como también G. T. PAgone, «Legal profesional privilege in the European Communities: The AM \& s Case and Australian Law», International and comparative law Quarterly, núm. 33 (1984), pp. 663-683.

${ }^{66}$ Planteamiento extractado de Richard Whish, Competition Law, op. cit., p. 268, quien, en respuesta al primer planteamiento, expone que la sentencia sostuvo que el privilegio existe, pero no sobre todos los documentos que relacionen a la empresa o asociación de empresas investigada y su representante, o respecto a toda la correspondencia que estos dos mantienen.

${ }^{67}$ AM E S Europe Limited vs. la Comisión, apartados 8 y 14, respecto de la consolidación del privilegio, y apartado 23 , acerca de la extensión temporal del mismo al expresar que éste abarca la comunicación anterior al proceso y la comunicación una vez ya iniciado el mismo, en los siguientes términos: «Esta protección debe entenderse en el sentido de que ampara de pleno Derecho cualquier correspondencia mantenida una vez ya incoado el procedimiento administrativo [...] La protección deberá poder extenderse igualmente a la correspondencia anterior relacionada con el objeto de dicho procedimiento».

${ }^{68} \mathrm{La}$ definición del secreto profesional objeto de la protección en desarrollo puede encontrarse en Richard WAINWRIGHT, «Application of EC competition rules by national courts», op. cit.; así como también en Eric GIPPINI-FournIER, «Legal Professional privilege in Competition Proceedings before the European Commission: Beyond the cursory Glance», Fordham International Law Journal, vol. 28, book 4 (2005), p. 970.

${ }^{69}$ AM E S Europe Limited vs. la Comisión, apartado 25, siendo un tema que por su sensibilidad ha generado debates y propuestas incluso de la autoridad comunitaria, sobre los cuales se podrá ahondar en las siguientes páginas y sobre las que llama la atención en este punto la realizada en razón del XIII Report on Competition Policy del año 1983, apartado 78. El documento está disponible para consulta en lengua inglesa en bttp://ec.europa.eu/competition/publications/annual_report/index.html. 
en varios países miembros a códigos de disciplina y similares no deberían incluirse como sujetos del privilegio $^{70}$.

Asimismo, al darle respuesta al segundo planteamiento acerca de los mecanismos idóneos a poner en marcha para delimitar si un documento se encuentra amparado o no por el privilegio ya consolidado, la jurisprudencia en desarrollo entendió que ni el agente involucrado, empresa o asociación de empresas, ni la Comisión misma, estaban en posición de tomar dicha decisión, puesto que el primero en ningún caso debería contar con ese poder, ya que otorgárselo vulneraria el Derecho comunitario y estaría en capacidad de distorsionar la aplicación de las disposiciones antitrust ${ }^{71}$, y empoderar a la Comisión a que tomara dicha decisión podría generar en todo caso una situación incómoda, en la cual incluso cuando algún agente de la autoridad comunitaria decidiese que un documento cuenta con dicho privilegio, la «investigada» pudiese ser reticente a aceptarlo, fundamentando que el haber tenido acceso a dicho material puede generar una influencia en la decisión de la Comisión.

Para solucionar una situación de disputa acerca de un material documental, la sentencia conceptuó que el Tribunal de Primera Instancia debería ser el encargado de dirimir ese tipo de controversias ${ }^{72}$, tanto si la inspección ${ }^{73}$ se ponía en marcha en razón de un mandamiento simple de la Comisión con anuencia del agente investigado, como si la misma se basaba en una decisión, caso en el cual también podría conocer de ella vía apelación ${ }^{74}$.

${ }^{70}$ Sobre dicho aspecto es de relevancia la Sentencia del Tribunal de Primera Instancia de 12 de diciembre de 1991, Hilti AG vs. la Comisión de las Comunidades Europeas, asunto T-30/89, texto disponible para consulta en http://eur-lex.europa.eu/LexUriServ/LexUriServ.do? uri=CELEX:61989A0030:ES:pdf, en la cual el Tribunal consideró que dicha circunstancia era excesivamente rígida, por lo que accedió a extender los límites del privilegio incluso a un documento interno en el cual un abogado con relación contractual con la investigada reportaba el concepto de un abogado externo sobre un asunto. Sobre el fallo vid. los comentarios que se encuentran en VAN BAEL y Jean-François Bellis, Competition Law of the European Community, op. cit., pp. 1023 y 1024.

71 Existiendo una clara coincidencia de conceptos entre el Tribunal y el gobierno de la República Francesa, que en el asunto hizo de coadyuvante de las pretensiones de la Comisión, en razón de la cual se otorgó concepto, a la par comprendido en el apartado 12 del fallo $A M$ \& S Europe Limited vs. la Comisión.

72 Suscitadas en razón de una reticencia de la empresa a otorgar los documentos requeridos a la Comisión, aduciendo estar amparados por el secreto profesional, que ella está obligada a probar, pues la carga de la prueba es suya. Tal y como puede verse en Alfonso-Luis Calvo Caravaca, Derecho antitrust europeo, t. I, Parte General. La competencia, Madrid, Colex, 2009, p. 630.

${ }_{73}$ Igualmente aplicable a aquellos casos en los cuales el poder de la Comisión es el de requerir información.

${ }^{74}$ AM E S Europe Limited vs. la Comisión, apartados 8 y 32. 
Con posterioridad al fallo $A M$ \& $S$ Europe Limited vs. la Comisión, otro grupo de pronunciamientos ha desarrollado los aspectos enunciados, siempre basando sus postulados en el primero y reafirmándolos, aunque con matices propios del dinamismo de la jurisprudencia ${ }^{75}$. Siendo ejemplo de ello la relevante sentencia Akzo Nobel Chemicals Ltd. E Akcros Chemical Ltd. vs. la Comisión de las Comunidades Europeas (en lo sucesivo Akzo Nobel Chemicals vs. la Comisión $)^{76}$, en la cual, si bien el Tribunal de Primera Instancia no cedió ante aspectos de gran rigidez hasta ese momento consolidados, como lo eran que la correspondencia entre los abogados In House y «su» empresa no se vieran cobijados por el secreto profesional ${ }^{77}$,

75 A saber, la decisión de la Comisión de 14 de diciembre de 1984, relativa a un procedimiento de aplicación del art. 85 del Tratado CEE (núm. IV/30.809, Jobn Deere) (Diario Oficial, núm. L 035/58), texto disponible para consulta en lengua inglesa en bttp://eur-lex. europa.eu/LexUriServ/LexUriServ.do?uri=OJ:L:1985:035:0058:0064:EN:pdf, sobre la cual se puede encontrar un análisis exhaustivo de los hechos y de los argumentos esgrimidos en relevancia con el tema mencionado en Alison Jones y Brenda SufRIN, EC Competition Law. Text, Cases and Materials, op. cit., p. 1185. Vid. también AKZO Chemie BV y AKZO Chemie UK Ltd. vs. la Comisión de las Comunidades Europeas, de 3 de julio de 1991, apartado 28, texto disponible para consulta en http://eur-lex.europa.eu/LexUriServ/LexUriServ. do? uri=CELEX:\%2061986O0062:ES:pdf; así como también la Sentencia del Tribunal de Justicia de las Comunidades europeas de 17 de octubre de 1989, asunto 85/87, Dow Benelux NV vs. la Comisión de las Comunidades Europeas, apartado 27, texto disponible para consulta en http://eur-lex.europa.eu/LexUriServ/LexUriServ.do?uri=CELEX:61987J0085:ES:pdf.

${ }^{76}$ Sentencia del Tribunal de Primera Instancia de 17 de septiembre de 2007, asuntos acumulados T-125/03 y T-253/03, texto disponible para consulta en bttp://eur-lex.europa.eu/LexUriServ/LexUriServ.do? uri=CELEX:62003A0125:ES:HTML. Sobre la misma, y de relevancia, el resumen que se encuentra en Alfonso-Luis Calvo Caravaca y María Pilar Canedo Arrillaga, «Casos escogidos de Derecho antitrust europeo», Estudios de Deusto, vol. 56, núm. 1 (enero-junio de 2008), pp. 236-242.

77 Tras la sentencia $A M$ E S Europe Limited vs. la Comisión, hasta llegar a la apelación al asunto Akzo Nobel Chemicals vs. la Comisión, se han suscitado reafirmaciones jurisprudenciales acerca del argumento elegido por el Tribunal de Justicia y por el Tribunal de Primera Instancia referente a que las comunicaciones que vinculen a abogados con relación laboral con la empresa no deben verse cobijadas por el privilegio del secreto profesional, como así lo son en orden cronológico el Auto del Tribunal de Justicia de las Comunidades Europeas, Sala Quinta, de 5 de diciembre de 1996, asunto C-174/96, Orlando Lopes vs. Tribunal de Justicia de las Comunidades Europeas, apartado 11, texto disponible para consulta en bttp:// eur-lex.europa.eu/LexUriServ/LexUriServ.do?uri=CELEX:6199600174:ES:pdf; la Sentencia del Tribunal de Justicia de las Comunidades Europeas de 16 de septiembre de 1999, asunto C-22/98, Solicitud de decisión prejudicial en el proceso penal contra Jean Claude Becu, Annie Verweire, Smeg NV y Adia Interim NV (en lo sucesivo Jean Claude Becu y otros), apartado 26, texto disponible para consulta en http://eur-lex.europa.eu/LexUriServ/LexUriServ. do? uri=CELEX:61998J0022:ES:pdf, y la Sentencia del Tribunal de Primera Instancia de 8 de diciembre de 1999, Euro-Lex European Law Expertise GmbH vs. la Oficina de Armonización del Mercado Interior (marcas, dibujos y modelos), asunto C-79/59, apartados 27 y 29, texto disponible para consulta en http://eur-lex.europa.eu/JOHtml.do?uri=OJ:C:2000:079:SOM:E N:HTML. Así como también la Decisión de la Comisión de 28 de enero de 1998, relativa a 
así como también que los abogados de terceros países ajenos a la Unión Europea no tuvieran dicho privilegio ${ }^{78}$, se marcaron pautas que han servido de sustento a aquellos que creen que dichas situaciones deben ser flexibilizadas y puestas en consideración del Tribunal competente para decidir si el legal privilege ampara cierto material documental o no, pues cortar de raíz la posibilidad de que cierta documentación que se encauce en dichas eventualidades esté a su vez cobijada por una obligación de secreto no parece la solución más conveniente, máxime cuando no es coherente considerar que la situación jurídica ha estado estancada.

El fallo Akzo Nobel Chemicals vs. la Comisión fue apelado y su respuesta se hizo esperar hasta el año $2010^{79}$, cuando el Tribunal de Justicia dio respuesta a las inquietudes que se habían planteado en la sentencia predecesora $^{80}$, volviendo a dejar claro que la confidencialidad entre abogados y clientes debía ser protegida como derecho fundamental, pero no en todas las circunstancias; toda vez que su ejecución se condiciona a un elemento esencial como lo es la independencia del abogado ${ }^{81}$, sin la cual las condiciones para el análisis del privilegio serían totalmente distintas.

un procedimiento de aplicación del art. 85 del Tratado CE, caso IV/35.733, Volkswagen vs. la Comisión de las Comunidades Europeas, publicada en el Diario Oficial, núm. L 124/60, de 25 de abril de 1998, texto disponible para consulta en bttp://eur-lex.europa.eu/LexUriServ/ LexUriServ.do? uri=OJ:l:1998:124:0060:0108:es:pdf.

${ }^{78} \mathrm{Al}$ tener suficiente sustento doctrinal y jurisprudencial cabe acotar que sorprende que, aun en la actualidad, las iniciativas de la misma Comisión hayan sido insuficientes para solventar esta situación paradójica, en la cual las comunicaciones con abogados independientes de un país ajeno a la Unión Europea no se ven cobijadas por el privilegio del secreto profesional; máxime cuando en algunos de esos países, como por ejemplo Estados Unidos, se garantiza ese privilegio a los abogados europeos a los efectos de la aplicación de su propia normativa antitrust, como así puede verse en Julian JoshuA, «It's a Privilege: Managing legal privilege in multijurisdictional antitrust Investigations», Competition Law Insight, 11 de diciembre de 2007, pp. 14-16.

${ }_{79}$ En la Sentencia del Tribunal de Justicia de las Comunidades Europeas de 14 de septiembre de 2010, asunto 550/07 P, apelación Akzo Nobel Chemicals Ltda. E Akcros Chemical Ltda vs. la Comisión de las Comunidades Europeas (en lo sucesivo apelación asunto Akzo Nobel Chemicals vs. la Comisión), texto disponible para consulta en bttp://eur-lex.europa.eu/ LexUriServ/LexUriServ.do? uri=CELEX:62007J0550:ES:HTML.

${ }^{80}$ Indispensable al respecto de este fallo resulta la lectura de Julia SuDEROw, «Nota sobre la sentencia del TJCE Akzo Nobel y otros de 14 de septiembre de 2010: límites al privilegio legal de las comunicaciones entre abogados y sus clientes», Cuadernos de Derecho Transnacional, vol. 3, núm. 1 (marzo de 2011), pp. 316-325, quien hace un resumen de las circunstancias del caso específico, poniendo de manifiesto las circunstancias factuales que desde el inicio acaecieron causando el conflicto.

${ }^{81}$ No pudiendo, por tanto, ser un abogado In House en base a ciertas razones que pueden verse sustentadas en las conclusiones aportadas por la abogado general Juliane Kokott, de fecha 29 de abril de 2010, en concreto los apartados 61 y 62. El documento está disponible para consulta en http://www.icam.es/docs/web3/doc/ABOGEMP_SecretoJULIANE_ 
Los argumentos elegidos en conclusión no desconocen bajo ningún concepto que el privilegio existe, pero lo delimitan, priorizando la salvaguarda del proceso investigador, y, por consiguiente, la protección de muchos, antes que el amparo de la empresa, que claramente, en ciertas circunstancias en las cuales el privilegio de secreto profesional no les cobije, estarán expuestas a procesos futuros basados en la información a la cual terceros tendrán acceso.

Lo cual inequívocamente, según mi concepto y el de muchos otros ${ }^{82}$, es benéfico, toda vez que la avalancha de conflictos que se producirían en las inspecciones o alrededor de los requerimientos de información sería insostenible ${ }^{83}$, pues se convertiría en un mecanismo de defensa regular elegido por las empresas para desgastar a la autoridad y para dilatar la resolución del asunto, convirtiendo el ejercicio de las atribuciones de la Comisión en un ejemplo de complejidad, ineficacia e inviabilidad, que de forma muy acertada el Tribunal de Justicia ha impedido que se suscite ${ }^{84}$.

A la par de la teoría, para cerrar este apartado cabe decir que las empresas y la Comisión son conscientes de la situación problemática que comúnmente se genera alrededor del material documental protegido por el privi-

KOKOTT.pdf. Igualmente Wouter P. J. WILs, Efficiency and European antitrust enforcement, op. cit., p. 20, pone de manifiesto que probar si la litigiosidad crece al otorgar el privilegio también a las comunicaciones con los abogados In House es posible si se hace un seguimiento a aquellos países miembros que cubren dichas comunicaciones en los mismos términos que aquellas que tienen como parte a un abogado independiente, a saber: Bélgica, Grecia, Irlanda y el Reino Unido.

${ }_{82}$ Como puede serlo, según se concluye de su lectura, Valentine KoraH, An introductory guide to EC Law and practice, op. cit., pp. 265-268, quien, en lo referente a este aspecto, enuncia las iniciativas que han sido seguidas por varias asociaciones y colegios de abogados europeos en busca de que, en concreto, las comunicaciones de los abogados internos con vinculación excepcional con la empresa también estén cobijadas por el privilegio en desarrollo; como lo son, en lo referente al asunto Akzo Nobel Chemicals vs. la Comisión y a su apelación, el Consejo de la Abogacía Europea (CCBE), el Consejo de la Abogacía de los Países Bajos, la European Company Lawyers Association, la Asociación Americana de Abogados de Empresa-sección europea y la Asociación Internacional de Colegios de Abogados, a las cuales igualmente se unieron el Reino Unido, los Países Bajos e Irlanda.

${ }_{83}$ Pues es de por sí una situación que conlleva normalmente múltiples conflictos de trasfondo, como así puede verse en Rafael AllendesalazAR CORCHO, «Confidencialidad de las comunicaciones abogado y cliente y eficacia de la labor inspectora: dos principios a la búsqueda de un equilibrio», Gaceta Jurídica de la Unión Europea y de la Competencia, núm. 7 (enero-febrero de 2009), p. 83, en donde se ponen de manifiesto las particularidades de las inspecciones en el ámbito español.

${ }^{84}$ También de importancia los comentarios que sobre el privilegio del secreto profesional se encuentran en Margaret Gray, Maya Lester, Cerry Darbon, Gerry Facenna, Christopher Brown y Elisa Holmes, Eu Law Competition law: procedures and remedies, Richmond, Oxford University Press, 2006, pp. 30 y ss. 
legio del secreto profesional, por lo que han ideado una conducta común, actualmente frecuente y en todo caso no contenciosa, que está permitiendo en el día a día darle una solución pragmática a este tipo de situaciones, como lo es que las empresas pongan la documentación a disposición de los oficiales encargados de la investigación enviándosela en un sobre sellado, para que éstos determinen si el privilegio se ve configurado en el material aportado o no ${ }^{85}$. Siendo una salida que, en cualquier caso, resulta ser un alivio para las partes y previene el uso de recursos evitables que tendrían que ser puestos en marcha en caso contrario.

\section{CONFIDENCIALIDAD Y USO DEL MATERIAL RECABADO POR LA COMISIÓN}

Una vez delimitados los parámetros que definen la existencia de cierto material protegido, que permite a las empresas ser reticentes a su entrega y disposición en favor de la Comisión en el curso de una inspección, es importante concretar el segundo punto, igualmente importante en lo que a la relación entre la inspección y el secreto profesional se refiere, tal y como en páginas previas se convino.

Dicho aspecto es el referente a la obligación que tiene la autoridad comunitaria de darle al material documental que ha sido acumulado en el curso de una investigación, conforme a los mecanismos dispuestos por el Reglamento $1 / 2003$, el uso específico para el que ha sido recabado y no

${ }^{85}$ Esta posibilidad es puesta de manifiesto como común y a la par benéfica para la investigación llevada a cabo por la Comisión, así como para el agente investigado, por Alison JONES y Brenda SufRIN, EC Competition Law. Text, Cases and Materials, op. cit., p. 1185; así como también por Richard Whish, Competition Law, op. cit., p. 269. Aunque sobre la misma se cree pertinente poner de manifiesto ciertas dudas que genera, pues plantea un conflicto acerca de: (i) la influencia que puede generar en el oficial de la Comisión la información que le es remitida en sobre sellado, de verla; (ii) la necesidad de, en esa eventualidad más que en cualquier otra, exigir un razonamiento en la decisión de la Comisión, en el cual se deje clara la justificación de los argumentos en los que ha soportando su decisión, los cuales no pueden tener relación alguna con la información protegida a la que tuvo acceso [como así lo expresa la Sentencia del Tribunal de Justicia de las Comunidades Europeas de 9 de noviembre de 1983, asunto 322/81, NV Nederlandsche Banden Industrie Michelin vs. la Comisión de las Comunidades Europeas (en lo sucesivo Michelin vs. la Comisión), apartados 9 y 10, texto disponible para consulta en http:// eur-lex.europa.eu/LexUriServ/LexUriServ.do?uri=CELEX:61981J0322:ES:pdf]; así como también acerca del (iii) poder de decisión que informalmente se le otorga al miembro de la Comisión para delimitar si efectivamente la información se encuentra amparada por el privilegio o no. Todos ellos puntos que van en contra de algunos de los fundamentos que han disciplinado el tema mencionado desde la Sentencia $A M$ \& S Europe Limited vs. la Comisión. 
otro ${ }^{86}$ que pueda generar un perjuicio a la empresa o asociación de empresas investigada, o incluso en el mercado mismo ${ }^{87}$.

La naturaleza de dicha prohibición ${ }^{88}$ tiene su sustento principal en el art. 339 del Tratado de Funcionamiento de la Unión Europea ${ }^{89}$, en el cual se les impone a los funcionarios de la Comisión la obligación de no divulgar información que «por su naturaleza, esté(n) amparada(s) por el secreto profesional» ${ }^{90}$.

De la lectura no sistemática y netamente individual del precepto enunciado es posible interpretar que el legislador europeo ha dejado en el aire ciertos aspectos esenciales y no ha otorgado los soportes suficientes que garanticen una línea de comportamiento en lo referente al manejo de la información, y lo que es más delicado, ha dejado a merced de la interpretación un tema como el actual que puede suscitar tantísimos perjuicios en el mercado mismo.

Lo expresado por el art. 339 llama la atención y genera muchos debates e interpretaciones a su alrededor, pues el texto no delimita a qué se refiere cuando habla de la «naturaleza de la información», así como tampoco arroja luces acerca de cuáles son puntualmente las situaciones en las que se configura una obligación de silencio por parte de los agentes de la Comisión ${ }^{91}$. Siendo una situación que, a su vez, se ve refrendada en

${ }^{86}$ Esta apreciación se hace toda vez que la restricción no se hace extensiva a la información que los miembros de la Comisión obtengan por medio de los medios informales, como lo pueden ser conversaciones con los oficiales de la autoridad comunitaria. De esta forma lo expone Valentine KoraH, An introductory guide to EC Law and practice, op. cit., p. 265.

87 Acerca de la obligación a cargo de los oficiales de la autoridad comunitaria de darle un uso exclusivo a la información, marcado por los propósitos que se incluyen en el mandamiento simple o en la decisión que pone en marcha los poderes de la Comisión, son de importancia los aportes jurisprudenciales encontrados en el fallo Michelin vs. la Comisión, apartado 8; Dow Benelux NV vs. la Comisión de las Comunidades Europeas, apartados 18 y 19, y el asunto Polypropyleen, apartados 472 y 473.

${ }_{88}$ Expuesta de forma puntual y ceñida a los instrumentos normativos pertinentes por Richard Whish, Competition Law, op. cit., p. 281.

${ }^{89} \mathrm{El}$ cual se transcribe por su relevancia: «Los miembros de las instituciones de la Unión, los miembros de los comités, así como los funcionarios y agentes de la Unión estarán obligados, incluso después de haber cesado en sus cargos, a no divulgar las informaciones que, por su naturaleza, estén amparadas por el secreto profesional y, en especial, los datos relativos a las empresas y que se refieran a sus relaciones comerciales o a los elementos de sus costes».

${ }^{90}$ En el artículo enunciado, además de verse cobijados los empleados de la Comisión, también se incluyen, en las mismas condiciones, todos los miembros de las instituciones de la Unión que puedan llegar a tener acceso a información de naturaleza susceptible.

${ }_{91}$ La falta de precisión al respecto ya había sido previamente resaltada en lo referente al art. 287 del TCE por Theofanis CHRISTOFOROU, «Protection of legal privilege in ECC competition law: The imperfections of a case», op. cit., pp. 1 y ss. 
la reproducción casi idéntica que hace el art. 28 del Reglamento 1/2003 del art. 339, en donde en iguales términos no se aporta explicación alguna al respecto ${ }^{92}$.

La aclaración de ambos artículos mencionados se ha venido dando de forma irregular en la normativa interna de algunos Estados miembros, donde se ha coincidido en expresar que tanto el art. 339 del Tratado como el art. 28 del Reglamento se refieren a aquella información que haya recabado el miembro de la Comisión en virtud de sus funciones, no siendo exclusivamente referente a secretos comerciales ${ }^{93}$.

Dichos avances domésticos, a su vez, se han visto complementados con la aparición de la Comunicación de la Comisión sobre la cooperación en la red de autoridades de la competencia ${ }^{94}$, la cual en su núm. 28, letra a), ha incluido en su texto ejemplos básicos que, si bien no han aclarado completamente los casos específicos que generan la obligación de prudencia de los agentes de la Comisión, sí que ha estrechado un poco el marco haciéndose eco de lo que la doctrina ya con antelación había planteado, al expresar que el término secreto profesional se refiere a «secretos comerciales y otro tipo de información confidencial».

Así las cosas, de haber obtenido la información en el desarrollo de las funciones que le son otorgadas por el Reglamento 1/2003 y por los textos comunitarios, así como estando dicha información encauzada en los parámetros del núm. 28 de la Comunicación enunciada en el párrafo anterior, los agentes y miembros de la Comisión deben darle un uso estricto marcado por los propósitos de la investigación; estando obligados a resguardar y proteger la información «sensible» incluso ante los Tribunales de los países miembros con los cuales tienen una obligación de cooperación, pudiendo solicitar a éstos garantías de que están en capacidad de proteger la información confidencial ${ }^{95}$.

92 El art. 28 del Reglamento 1/2003, siendo una extensión del art. 339 del Tratado de Funcionamiento de la Unión Europea, no se refiere a todos los miembros de las instituciones de la Unión, sino que centra la obligación de secreto en la Comisión, las autoridades nacionales de competencia de los Estados miembros, así como en los individuos que se vean empoderados por éstas para darle cumplimiento a las funciones a su cargo.

${ }_{93}$ Valentine KoraH, An introductory guide to EC Law and practice, op. cit., pp. $265-268$.

${ }_{94}$ Publicada en el Diario Oficial de la Comunidad Europea, núm. C 101/43, de 27 de abril de 2004.

${ }^{95}$ Conclusión que es posible extraer de la lectura de Ivo VAN BaEL y Jean-François BeLlis, Competition Law of the European Community, op. cit., pp. 1031-1033, donde, basados en la jurisprudencia comunitaria, los autores reafirman la necesaria protección de la información que debe ser llevada a cabo por los funcionarios de la Comisión en la actua- 
No obstante la claridad que se logra tras el párrafo anterior, otra disposición del Reglamento 1/2003 emerge generando algo de dudas al respecto, en concreto acerca del alcance de la obligación de los funcionarios dispuesto en el art. 28, como lo es la del núm. 2 del art. 27, en la cual se otorga el poder a la Comisión de difundir «la información necesaria para demostrar una infracción». Disposición que, en apariencia, ampara lo suficiente a los oficiales de la autoridad comunitaria para justificar en ocasiones la transmisión de información confidencial.

Es claro, a tenor del art. 27, que hay un resquicio utilizable por la Comisión para desconocer, así sea de forma parcial, la obligación a su cargo de resguardar aquella información que pueda ser interpretada como confidencial cuando entienda que es menester hacerla pública para descubrir y demostrar una infracción a las normas antitrust; máxime al observar que el art. 28 del Reglamento 1/2003, en su núm. 2, dice que la obligación de secreto existe sin prejuicio del uso de la información previsto en varios artículos del Reglamento ${ }^{96}$, entre los cuales se encuentra el art. $27^{97}$.

Si bien la grieta existe, creo que la misma es una protección especial del interés general que sólo debe ser puesta en marcha en situaciones particulares que lo ameriten y que debe ser interpretada con cautela, amén de no convertirla en una configuración del «todo vale» o del «fin justifica los medios», toda vez que aparentemente no extrae por sí sola de las obligaciones de los miembros de la Comisión aquella referente a evaluar en cada situación particular ${ }^{98}$ cuáles pueden ser los efectos que está en capacidad de conllevar hacer públicos documentos de especial sensibilidad ${ }^{99}$; como así se extrae de

lidad en términos de eficiencia y rigurosidad, que no eran operantes bajo la vigencia del Reglamento 17/1962.

${ }^{96}$ A saber, los arts. 11, 12, 14 y 15.

${ }_{97}$ Posición reafirmada en la Comunicación sobre cooperación en la red de autoridades de competencia, núm. 28, letra $a$ ), al expresa que: «El interés legítimo de las empresas por la protección de sus secretos comerciales no puede ir en perjuicio de la divulgación de la información necesaria para verificar una infracción de los arts. 81 y 82 del Tratado».

98 Dentro de los exámenes a realizar en todos los casos para delimitar el alcance de la protección que arrope cierto material documental está uno de importancia resaltado por la jurisprudencia, como es el de sopesar dicha protección con los derechos de defensa, para así delimitar hasta qué punto estos últimos se pueden ver menoscabados. Como así puede verse en Rene BARENTs, Directory of EC case Law on Competition, Alphen aan den Rijn (Holanda), Kluwer Law International, 2007, p. 593, quien enuncia un grupo de sentencias relevantes sobre el aspecto descrito.

${ }_{99}$ De esta opinión es Jose Luis GIL IBÁÑ̃EZ, «La Comisión y la aplicación del Derecho comunitario de la competencia», op. cit., p. 138, quien entiende que en oportunidades la publicidad de cierto material o información puede generar más perjuicios que los de la transgresión misma. 
las actuaciones de la autoridad comunitaria de la competencia, donde efectiva y comúnmente antes de divulgar cualquier información se tasan los beneficios y perjuicios que se pueden generar en cada evento ${ }^{100}$.

La jurisprudencia ha tenido un papel protagónico que se puede palpar, además de en los fallos enunciados a lo largo de este apartado, en otro grupo de sentencias que han intentado disciplinar y concretar suficientemente la obligación de la Comisión en el manejo de la información, con el ánimo de delimitar, entre otros, aspectos como el suscitado entre el art. 28 y el núm. 2 del art. $27^{101}$.

La conclusión tras la lectura de todos ellos es que, a pesar de las dudas que se puedan generar y de los choques de principios e interés que potencialmente se pueden suscitar en razón de la protección de información confidencial, la obligación de los oficiales de la Comisión de no divulgar cierta información sensible amparada por el secreto efectivamente existe y genera,

${ }^{100}$ Sobre dicho estudio son relevantes los comentarios realizados por Rene BARENTS, Directory of EC case Law on Competition, op. cit., p. 594, quien, basado en la jurisprudencia comunitaria, expone que, aun en los casos en los cuales los involucrados pongan de manifiesto ante la Comisión la existencia de material sensible arropado por el secreto profesional, comercial o similar, y lo señalen inequívocamente, la Comisión debe realizar, pues dicha actuación de terceros no le libera de ello conforme a la obligación que le impone el art. 339 del Tratado de Funcionamiento de la Unión Europea, un examen propio en el cual se analice todo el material que sea interpretado por la autoridad como arriesgado no sólo por su naturaleza, sino por la situación particular en disputa, los implicados, etc. Planteamiento soportado por el fallo del Tribunal de Primera Instancia de 25 de octubre de 2005, asunto T-5/02, Tetra Laval BV vs. la Comisión de las Comunidades Europeas, apartado 101, texto disponible para consulta en http://eur-lex.europa.eu/LexUriServ/LexUriServ. do? uri=CELEX:62002A0005:ES:pdf.

${ }^{101}$ Así, por ejemplo, no pueden ser obviados los aportes realizados en el Fallo del Tribunal de Justicia de las Comunidades Europeas de 30 de octubre de 1978, asuntos acumulados 209/78 R a 215/78 R y 218/78 R, Heintz van Landewyck SARL y otros vs. la Comisión de las Comunidades Europeas, texto disponible para consulta en lengua inglesa en bttp:// eur-lex.europa.eu/LexUriServ/LexUriServ.do?uri=CELEX:6197800209\%20:EN:pdf; la Sentencia del Tribunal de Justicia de las Comunidades Europeas de 7 de noviembre de 1985, asunto 145/83, Stanley George Adams vs. la Comisión de las Comunidades Europeas, apartado 34, texto disponible para consulta en http://eur-lex.europa.eu/LexUriServ/LexUriServ. do? uri=CELEX:61983J0145:ES:pdf; AKZO Chemie BV vs. la Comisión de las Comunidades Europeas, apartado 28; SEP vs. la Comisión, apartados 30 y 36; así como las Sentencias del Tribunal de Primera Instancia de 18 de septiembre de 1996, asunto T-353/94, Postbank NV vs. la Comisión de las Comunidades Europeas, apartado 86, texto disponible para consulta en http://eur-lex.europa.eu/LexUriServ/LexUriServ.do?uri=CELEX:61994A0353:\%20 ES:HTML; de 6 de julio de 2000, asunto T-62/98, Volkswagen AG vs. la Comisión de las Comunidades Europeas, apartado 279, y de 30 de mayo de 2006, asunto T-198/03, Bank Austria Creditanstalt vs. la Comisión de las Comunidades Europeas, apartado 29, texto disponible para consulta en lengua inglesa en bttp://eur-lex.europa.eu/LexUriServ/LexUriServ.do?u $r i=$ CELEX:62003A0198:EN:HTML. 
a su vez, un deber de conducta ineludible a seguir por los miembros de la autoridad en los procesos a su cargo, como lo es el de adoptar mecanismos eficientes que impidan en todos los casos la configuración de un menoscabo a los intereses de una empresa, bien porque se hace público su Know How, los precios de sus insumos, proveedores ${ }^{102}$, o simplemente porque cualquier información confidencial que le afecte pasa a ser de dominio general ${ }^{103}$.

\section{EL DERECHO A GUARDAR SILENCIO Y A NO AUTOINCRIMINARSE EN EL CURSO DE UNA INVESTIGACIÓN DE LA COMISIÓN EUROPEA EN MATERIA DE COMPENTENCIA}

Así como en ramas jurídicas como la penal están más que interiorizados los derechos a permanecer en silencio y a no declarar contra sí mismo como parte de los privilegios con los que cuenta el imputado para no responder al ser preguntado acerca de aspectos que de exponerse pueden configurar una admisión de su infracción, en lo que a asuntos de la Competencia se refiere, dicha premisa debería estar más que interiorizada, y a la par prevista en los instrumentos normativos de relevancia.

Los conflictos se inician cuando sucede exactamente lo contrario y a la vez los instrumentos normativos prevén situaciones contrarias a dicho privilegio, generando una confusión de importancia que sirve de pistoletazo de salida a gran variedad de interpretaciones a su alrededor ${ }^{104}$.

102 Mark FurSE, Competition law of the EC and UK, op. cit., p. 97, enuncia este tipo de información al entender que lo esencial es que la obligación a cargo de los funcionarios de la Comisión impida la configuración de ayuda comercial de la cual pueda sacar provechos económicos un tercer competidor.

${ }^{103}$ La forma de hacer públicos los documentos, de ser decidido así por la Comisión, también comporta un control a la autoridad comunitaria, toda vez que se exige, como requisito indispensable, que la divulgación se haga por medio de una decisión específica e independiente tomada por la Comisión para comunicar a terceros la información recabada. Decisión que podrá ser recurrida conforme al art. 263 del Tratado de Funcionamiento de la Unión Europea y que en cualquier caso no debe ser confundida, y mucho menos coincidir en el mismo cuerpo, con la decisión que pone fin al proceso. Tal y como así puede concluirse de la lectura de $A K Z O$ Chemie BV vs. la Comisión de las Comunidades Europeas, apartado 29, donde se añade al respecto que: «Habida cuenta del perjuicio en extremo grave que podría resultar de la comunicación irregular de documentos a un competidor, la Comisión debe, antes de ejecutar su decisión, dar a la empresa la posibilidad de acudir al Tribunal para que se revisen las apreciaciones de que se trata e impedir de esta forma que se efectúe la comunicación».

104 Sobre los debates y las percepciones doctrinales puede verse Christopher BeLLAmY, Graham Child y Enric PICAÑol, Derecho de la competencia en el mercado común, op. cit., 
En resumidas cuentas, ése es el caso del Reglamento 1/2003, el cual, por un lado, no contiene referencia alguna, directa o indirecta, a un privilegio tal o similar al de no declarar contra sí mismo, y por el otro, otorga poderes a la Comisión para requerir información ${ }^{105}$ y para solicitar a los empleados de una empresa o asociación de empresas, en el curso de una inspección, las explicaciones sobre hechos o documentos relacionados con el objeto y finalidad de la diligencia ${ }^{106}$. Añadiendo multas sancionadoras y coercitivas en caso de resistirse al ejercicio de aquellos poderes mencionados ${ }^{107}$ que hacen más compleja la delimitación de la existencia o no en el ámbito europeo de un privilegio a permanecer en silencio cuando lo contrario signifique inculparse.

El silencio del Reglamento, como en otras circunstancias, ha generado que se hayan producido aproximaciones divergentes por parte de las Cortes Europeas, inclusive la de Derechos Humanos, en busca de delimitar si el privilegio se configura en Europa o aún no es un mecanismo de defensa operativo. Los argumentos elegidos no sólo se han erigido alrededor de las condiciones en las cuales dicho privilegio puede ser puesto en marcha, sino también en la existencia misma de dicho privilegio en lo que a defensa de la competencia se refiere, y en concreto alrededor de los poderes de investigación de la Comisión.

En los asuntos Orkem S. A. vs. la Comisión de las Comunidades Europeas (en lo sucesivo Orkem) ${ }^{108}$ y Solvay vs. la Comisión de las Comunidades Europeas ${ }^{109}$, el Tribunal de Justicia de las Comunidades Europeas se mani-

p. 690; Bo Vesterdorf, «Legal Professional Privilege and the Privilege Against Self-Incrimination in EC Law: Recent Developments and Current Issues», Fordham International law journal, vol. 28, núm. 4 (2004); Ivo VAN BAEL y Jean-François Bellis, Competition Law of the European Community, op. cit., pp. 1027-1031; Angus MACCulloch, «The privilege against self-incrimination in competition investigations: theoretical foundations and práctical implications», Legal Studies, vol. 26, núm. 2 (junio de 2006); Richard Whish, Competition Law, op. cit., p. 267, y Peter WILLIS, «The Privilege against self-incrimination in competition investigations», artículo presentado en el Competition, Regulation and Trade Group Taylor Wessing, 27 de enero de 2006.

${ }^{105}$ En razón de la ya suficientemente expuesta atribución incluida en el art. 18 del Reglamento.

${ }_{106}$ Como así puede comprobarse en el mencionado art. 20, núm. 2, letra e), del Reglamento 1/2003.

107 A saber, aquellas previstas en los arts. 23 y 24 del Reglamento 1/2003.

108 Sentencia del Tribunal de Justicia de las Comunidades Europeas de 18 de octubre de 1989, asunto 374/87, Orkem S. A. vs. la Comisión de las Comunidades Europeas, texto disponible para consulta en http://eur-lex.europa.eu/LexUriServ/LexUriServ. do? uri=CELEX:61987J0374:ES:pdf.

109 Sentencia del Tribunal de Justicia de las Comunidades Europeas de 18 de octubre de 1989, asunto 27/88, Solvay vs. la Comisión de las Comunidades Euro- 
festó sobre este aspecto tomando una posición llamativa, toda vez que, por un lado, si bien planteó que efectivamente las empresas podían declinar responder preguntas basadas en que contestarlas configuraría una autoinculpación, por el otro, afirmó que dicho privilegio era limitado en el Derecho comunitario y que, por tanto, no empoderaba a las empresas o asociaciones de empresas investigadas a erigirlo como mecanismo de defensa para negarse a entregar documentos que podían serle útiles a la Comisión para demostrar el acaecimiento de una infracción a las normas de libre competencia que le vinculara a sí misma o a otros ${ }^{110}$.

El Tribunal, entre sus argumentos predilectos, puso de manifiesto la ausencia de preceptos normativos que le incluyeran, toda vez que el Reglamento 17/1962 tampoco decía nada al respecto, y a su vez expuso que el privilegio a favor de las empresas sólo podía configurarse en aquellas circunstancias en las cuales la atribución de la Comisión de solicitar respuestas fuera de una diligencia de inspección o en la inspección misma se pusiese en marcha en razón de una decisión de la autoridad comunitaria y no como resultado de un mandamiento simple.

La situación problemática y la disputa se suscitó, toda vez que, además de los argumentos del Tribunal de Justicia, el Tribunal Europeo de Derechos Humanos también se expresó al respecto ${ }^{111}$, en concreto en el fallo Funke vs. Francia ${ }^{112}$, en el cual planteó una solución diversa basada en el Convenio para la Protección de los Derechos Humanos y de las Liber-

peas, texto disponible para consulta en http://eur-lex.europa.eu/LexUriServ/LexUriServ. do? uri=CELEX:61988J0027:ES:pdf.

110 Sentencia Orkem, apartado 34: «Por consiguiente, aunque para preservar la eficacia de los apartados 2 y 5 del art. 11 del Reglamento núm. 17 la Comisión tenga la potestad de obligar a la empresa a que facilite toda la información necesaria relacionada con hechos de los que pueda tener conocimiento y a que le presente, si fuere preciso, los documentos correspondientes que obren en su poder, incluso si los mismos pueden servir para probar contra ella o contra cualquier otra empresa la existencia de una conducta contraria a la competencia, la referida institución no puede, mediante una decisión de solicitud de información, vulnerar el derecho de defensa reconocido a la empresa».

${ }_{111}$ Sobre los comentarios de dicho Tribunal, Paul Craig y Gráinne DE BúrCA, EU Law. Text, cases and materials, 4. ${ }^{a}$ ed., New York, Oxford University Press, 2008, pp. 393 y 394.

112 Sentencia núm. 10828/84, de 25 de febrero de 1993, Funke vs. Francia, texto disponible para consulta en lengua inglesa en bttp://cmiskp.echr.coe.int/tkp197/view. asp? item $=1$ Eportal=hbkmEaction $=h$ tmlEhighlight $=F U N K E$ Esessionid $=72886579$ Eskin $=h$ udoc-en. Sobre el fallo mencionado y los parámetros del privilegio a permanecer en silencio, los comentarios de Walter VAN OvERBEEK, «The Reight to remain silent in competition investigations: The Funke decision of the Court of Human Rights Makes Revision of the ECJ's Case Law Necessary», European Competition Law Review, vol. 15, núm. 3, 1994, pp. 127 y ss. 
tades Fundamentales, y en especial en su art. $6^{113}$, relativo al «derecho a un proceso equitativo», aduciendo que el privilegio a permanecer en silencio y a no contribuir en su propia inculpación debe otorgársele a cualquiera que esté siendo imputado en la comisión de una infracción ${ }^{114}$, tanto en lo que se refiere a responder preguntas, como en lo referente a proporcionar documentos que puedan generar dicho efecto autoincriminatorio ${ }^{115}$.

Los Tribunales Europeos no han cedido a los argumentos elegidos por el Tribunal Europeo de Derechos Humanos y han mantenido su perspecti$\mathrm{va}^{116}$, erigiendo como principal baza de su posición las obligadas limitaciones que debe tener el privilegio, el cual, interpretan, en ningún caso debe ser absoluto ${ }^{117}$, pues entienden que dicho reconocimiento extrapolaría los

${ }_{113}$ El artículo mencionado fue igualmente abordado en el fallo Orkem, en su apartado 30, en el cual el Tribunal de Justicia determinó que si bien el privilegio podía ser invocado en un proceso, de su texto y de la jurisprudencia del Tribunal Europeo de Derechos Humanos no se desprendía el reconocimiento del derecho en disputa (al parecer basado en la ausencia de apartado taxativo sobre el). Planteamiento que, a su vez, fue reafirmado por el fallo del Tribunal de Primera Instancia de 29 de abril de 2004, asuntos acumulados T-236/01, T-239/01, T-244/01, T-245/01, T-246/01, T-251/01 y T-252/01, Tokai Carbon Co. Ltd., SGL Carbon AG, Nippon Carbon Co. Ltd. y otros vs. la Comisión de las Comunidades Europeas (en lo sucesivo Tokai Carbon y otros vs. la Comisión), apartado 404, texto disponible para consulta en http://eur-lex.europa.eu/LexUriServ/LexUriServ. do? uri=CELEX:62001A0236:ES:PDF; así como por la Sentencia del Tribunal de Justicia de las Comunidades Europeas que resolvió la casación del caso de 29 de junio de 2006, asunto C-301/04 P, La Comisión de las Comunidades Europeas vs. SGL Carbón AG y otros, apartado 10, texto disponible para consulta en http://eur-lex.europa.eu/LexUriServ/LexUriServ. do? uri=CELEX:\%2062004J0301:ES:PDF.

${ }^{114}$ Los planteamientos al respecto realizados en la Sentencia Funke vs. Francia fueron a su vez refrendados en fallos posteriores del Tribunal Europeo de Derechos Humanos, donde se defendió que, a pesar de la falta de precepto taxativo que incluyera en la norma el privilegio, el mismo existía sin duda en razón del art. 6 del Convenio. Dichas sentencias son, a saber, de 8 de febrero de 1996, John Murray vs. el Reino Unido, apartado 45; de 17 de diciembre de 1996, Saunders vs. el Reino Unido, apartado 71, y de 3 de agosto de 2001, $J B$ vs. Suiza, apartado 64, todas ellas disponibles para consulta en lengua inglesa en $b t t p: / /$ cmiskp.echr.coe.int/tkp197/search.asp? skin=\%20hudoc-en.

${ }_{115}$ Como así puede extraerse de la lectura de Funke vs. Francia, apartado 44.

116 Los pronunciamientos de las Cortes Europeas parecen ceñirse claramente a lo expuesto por el Reglamento 1/2003, donde si bien nada se dice en su articulado sobre este privilegio, sí que hay un texto de relevancia en el núm. 23 inicial, donde se abre una puerta a la interpretación al expresar: «No podrá obligarse a las empresas a admitir que han cometido una infracción, pero éstas estarán obligadas en cualquier caso a responder a preguntas relativas a los hechos y a proporcionar documentos, aun cuando dicha información pueda ser utilizada en contra de dichas u otras empresas para constatar la existencia de una infracción».

117 Sentencia del Tribunal de Primera Instancia de 20 de febrero de 2001, asunto T-112/98, Mannesmann-Robrenwerke AG vs. la Comisión de las Comunidades Europeas (en lo sucesivo Mannesmannrobren vs. la Comisión), apartado 66. 
derechos de defensa de las empresas en el proceso llevado ante la Comisión ${ }^{118}$ y con seguridad constituiría un obstáculo para el cumplimiento de las funciones de aplicación de la normativa antitrust por parte de dicha autoridad, conllevando una pérdida de la eficiencia en la protección llevada a cabo por ésta ${ }^{119}$.

De tal manera, las limitaciones que las Cortes han entendido deben ser impuestas a este privilegio se basan en delimitar bajo qué circunstancias las empresas podrán invocarlo, ya que, en su opinión, el manejo es diverso si el escenario es el de una solicitud de documentos o si es el de una formulación de preguntas ${ }^{120}$.

Así, por ejemplo, en lo referente a solicitar documentación a una empresa, los argumentos han sido que en ningún caso las investigadas podrán invocar el derecho a permanecer en silencio y que, por el contrario, en todas las circunstancias deberán proveer lo solicitado, incluso si el establecimiento de la infracción y su participación en ella están comprendidos en el material requerido ${ }^{121}$.

Por el contrario, acerca de las preguntas formuladas por la Comisión, las Cortes las han interpretado en un sentido opuesto, toda vez que han

118 Acerca de los principios fundamentales del proceso y los derechos a favor de las empresas en este tipo de procedimientos en el nivel comunitario ante la Comisión, puede verse Rosario LEÓN JIMÉNEZ, «Los derechos fundamentales de las empresas en el procedimiento de competencia comunitario», en Luis Ortiz Blanco y Adriana Pascual Sequeros (coords.), Derecho de la competencia europeo y español, vol. III, Madrid, Dykinson, 2002, pp. 115 y ss.

119 Esta línea conceptual puede verse en la relevante sentencia Mannesmannrobren vs. la Comisión, apartados 66 y 67, texto disponible para consulta en http://eur-lex.europa.eu/ LexUriServ/LexUriServ.do? uri=CELEX:61998A0112:ES:pdf; así como también en la Sentencia del Tribunal de Justicia de las Comunidades Europeas de 7 de enero de 2004, asuntos acumulados C-204/00 y otros, Aalborg Portland, Irish Cement Ltd., Ciments français SA, Italcementi - Fabbriche Riunite Cemento SpA, Buzzi Unicem SpA y Cementir - Cementerie del Tirreno SpA vs. la Comisión de las Comunidades Europeas (en lo sucesivo Aalborg Portland y otros vs. la Comisión), apartado 208, texto disponible para consulta en lengua inglesa en http://eur-lex.europa.eu/LexUriServ/LexUriServ.do? uri=CELEX:62000J0204:EN:HTML.

${ }^{120}$ Además de dicha diferenciación, las Cortes han entendido que el procedimiento seguido ante la Comisión no es uno de aquellos procesos que se encuentran comprendidos en el art. 6 del Convenio para la Protección de los Derechos Humanos y de las Libertades Fundamentales, conllevando la existencia limitada del privilegio a permanecer en silencio en este tipo de procedimientos. Posición que puede verse en el apartado 31 del fallo Orkem, así como también en algún sector de la doctrina que ha centrado su apreciación sobre el privilegio a permanecer en silencio alrededor de esta circunstancia, por entender que, resuelto este parámetro, no serían necesarios argumentos diversos para contradecir lo expuesto por el Tribunal Europeo de Derechos Humanos. Como así puede verse en Alison Jones y Brenda Sufrin, EC Competition Law. Text, Cases and Materials, op. cit., pp. 1176 y 1177.

121 Como así se extrae de la lectura de La Comisión de las Comunidades Europeas vs. SGL Carbón AG y otros, apartado 44, donde se reafirmo dicha óptica de las Cortes Europeas. 
comprobado que en ocasiones dichas preguntas van más allá de los poderes de la Comisión y de las atribuciones mismas que se le otorgan para llevar a cabo una investigación, ya sea por ser sugestivas, engañosas, conclusivas, ambiguas o similares ${ }^{122}$. Entendiéndolo, han dicho que el privilegio a permanecer en silencio y a dejar sin respuesta los cuestionamientos se configura en aquellos casos en los cuales la pregunta formulada es de alguno de los estilos descritos ${ }^{123} \mathrm{o}$, en su caso, cuando se hubiese forzado al personal de la empresa a dar respuestas que impliquen una admisión de su participación en una transgresión a las normas de libre competencia que por atribución debe ser probada por la autoridad ${ }^{124}$.

De la misma forma, las Cortes han manifestado que el derecho en favor de las empresas también puede ser puesto en marcha por éstas cuando son preguntadas con respecto a hechos y no a documentos, pues, en la práctica, las preguntas netamente «factuales» pueden marcar diferencias y permitir a la Comisión, una vez respondidas, probar la responsabilidad de la empresa en el ilícito.

La diferencia entonces entre la óptica de las Cortes Europeas (Tribunal de Justicia y Tribunal de Primera Instancia) y la del Tribunal Europeo de Derechos Humanos se basa en que, en razón de los fallos y concepto de este último, cualquier acción positiva de una autoridad que potencialmen-

${ }^{122}$ Lo importante es determinar, con el ánimo de saber si efectivamente una pregunta menoscaba el derecho de las empresas, si una respuesta efectivamente sería equivalente a la admisión de la infracción, como así se expone en la Sentencia del Tribunal de Primera Instancia de 27 de septiembre de 2006, asunto T-59/02, Archer Daniels Midland Co. vs. la Comisión de las Comunidades Europeas, apartado 262, en los siguientes términos: «La protección de este derecho supone, en caso de discrepancia acerca del alcance de una pregunta, que se compruebe si una respuesta del destinatario equivaldría efectivamente a la confesión de una infracción, de manera que se vulneraría el derecho de defensa».

${ }^{123}$ Ejemplos de esta postura cada vez mas interiorizada, que ya encuentra soportes jurisprudenciales, pueden ser encontrados en Ivo VAN BAEL y Jean-François BeLLIs, Competition Law of the European Community, op. cit., p. 379.

124 El reconocimiento de la infracción, de darse, debe ser resultado de la voluntad individual de la empresa y en ningún caso resultado de un constreñimiento efectuado por los funcionarios de la Comisión, quienes deben evitar en todos los casos dar una impresión equivocada que haga entender que están obligando con sus cuestionamientos a reconocer la participación en la infracción. Como así se extrae de un grupo de fallos, a saber, del Tribunal de Justicia de las Comunidades Europeas de 14 de julio de 2005, asuntos acumulados C-65/02 y C-73/02, ThyssenKrupp Stainless GmbH y ThyssenKrupp Acciai speciali Terni SpA vs. la Comisión de las Comunidades Europeas (en lo sucesivo ThyssenKrupp vs. la Comisión), apartado 52, texto disponible para consulta en http://eur-lex.europa.eu/LexUriServ/LexUriServ.do? uri=CELEX:62002J0065:ES:PDF; el fallo Polypropyleen, apartados 455 y 457; La Comisión de las Comunidades Europeas vs. SGL Carbón AG y otros, apartado 42; el fallo Orkem, apartado 35, y el fallo Polypropyleen, apartado 449. 
te esté en capacidad de conllevar la aceptación de la culpa por parte de un «imputado» puede comportar la decisión de guardar silencio ${ }^{125}$; mientras que para aquéllas, sólo algunas acciones de la Comisión pueden justificar el ejercicio del derecho, toda vez que no plantear ciertos límites y otorgar a los agentes un privilegio «total» como el que está en estudio iría más allá de lo que es necesario para garantizar el apropiado derecho de defensa en favor de las empresas ${ }^{126}$.

La divergencia ${ }^{127}$ lo que ha venido a dejar claro es que, a pesar de la disputa, la Comisión, en los asuntos que se susciten alrededor de los arts. 101 y 102 del Tratado de Funcionamiento de la Unión Europea, debe otorgar el privilegio a guardar silencio y a no autoincriminarse de forma limitada y en ciertas eventualidades ya previamente descritas, pues las apreciaciones del Tribunal Europeo de Derechos Humanos sobre el tema no se hacen extensivas a las disputas de competencia ${ }^{128}$.

No obstante, nuevas vías de disputa son puestas de manifiesto por la doctrina acerca del presente tema al expresar que la situación actual es en todo caso cambiante y puede generar mutaciones en el sistema de protección de la competencia. Los autores expresan que, en razón de la modernización y la cabida que en el contexto actual tiene el Private enforcement del derecho de la competencia, los Tribunales de los países miembros ${ }^{129}$ pueden interpretar el derecho y otorgar el privilegio a los implicados siguiendo la línea marcada por el Tribunal Europeo de Derechos Humanos y no

125 Funke vs. Francia, apartado 71.

126 El cual se encuentra suficientemente garantizado en razón de las múltiples oportunidades que tienen las empresas para manifestar su parecer en varios momentos del proceso seguido ante la Comisión desde la apertura del mismo, e incluso previamente, mediante comunicaciones informales y similares; pudiendo poner en marcha los mecanismos de defensa en referencia a documentos, preguntas que le son formuladas y, en general, estando capacitadas para replicar los planteamientos de la autoridad comunitaria. Como así se encuentra estipulado en la sentencia Polypropyleen, apartado 448.

${ }_{127}$ El desarrollo de los postulados erigidos por el Tribunal de Primera Instancia y el Tribunal de Justicia de las Comunidades Europeas puede encontrarse en Rene BARENTS, Directory of EC case Law on Competition, op. cit., pp. 528-530.

${ }^{128}$ En adición a los fallos mencionados sobre el tema cabe enunciar algunas otras sentencias que han soportado los planteamientos de las Cortes Europeas, en contraposición a lo dicho por el Tribunal Europeo de Derechos Humanos, a saber, las Sentencias del Tribunal de Primera Instancia de 21 de junio de 2006, asunto T-47/02, Danzer vs. el Consejo de la Unión Europea, texto disponible para consulta en http://eur-lex.europa.eu/LexUriServ/LexUriServ.do?uri=CELEX:62002A0047:ES:pdf; el asunto Cimenteries CBR y otros vs. la Comisión de las Comunidades Europeas, apartado 734, y el asunto Société générale vs. la Comisión de las Comunidades europeas, apartado 74.

${ }^{129}$ En razón de ser, todos aquellos Estados firmantes del Convenio para la Protección de los Derechos Humanos y de las Libertades Fundamentales. 
aquélla trazada por las Cortes Europeas; siendo un aspecto que creen debe ser resuelto por algún instrumento normativo o por la jurisprudencia, de suscitarse la oportunidad, antes de que asuntos de Forum Shoping condicionen la actuación de la Comisión ${ }^{130}$.

\section{CONCLUSIONES}

Al finalizar con este privilegio limitado de los agentes investigados y habiendo sido resaltados todos y cada uno de los pormenores esenciales que envuelven las atribuciones de investigación actuales de la Comisión en materia de inspección, no es arriesgado concluir que la autoridad comunitaria actualmente se encuentra en una posición privilegiada, superior y de inmensa relevancia, que le faculta para cumplir su labor en términos de eficiencia y preeminencia frente a los demás Enforcement Bodies que el mismo Reglamento ha empoderado para cumplir la labor de protección de la competencia en el ámbito europeo.

Contar con una ampliación significativa de sus poderes de investigación, así como envolver dichas facultades en la idoneidad, utilidad y la conveniencia, extrayendo de su entorno circunstancias que dificulten el descubrimiento y desmantelamiento efectivo de las conductas contrarias a la normativa de libre competencia, le ha equiparado a otra autoridad igualmente relevante, como lo es la Federal Trade Commission de Estados Unidos, de la cual se han aprovechado experiencias que a día de hoy enriquecen los poderes de la autoridad comunitaria de la competencia en Europa, y que conjuntamente, por ser representantes en el tema de dos de las economías de mayor trascendencia, deben marcar una pauta de importancia en la estructuración de un sistema cada vez más internacional de defensa de la competencia, en el cual el tránsito informativo, la cooperación y el trabajo conjunto en materia de investigación no sean aspectos restrictivos de la Red de Autoridades de Competencia en Europa.

Hay rotunda claridad acerca de la necesidad de fortalecer los instrumentos cooperativos que unen a la autoridad supranacional desarrollada con las autoridades de corte administrativo del nivel nacional, e incluso con los jueces nacionales merced al private enforcement ya instaurado en

${ }^{130}$ Un ejemplo de la situación mencionada es resaltado por Ivo VAN BAEL y JeanFrançois BelLis, Competition Law of the European Community, op. cit., p. 1031, nota 383, en donde se pone en manifiesto la situación suscitada en Francia alrededor del asunto Sony France y Philips France vs. Avantage y otros. 
Europa. La discrecionalidad en el apoyo y en la colaboración institucional es prohibitiva entre tanto no se alcancen unos niveles de coherencia que impidan que la doble asignación de recursos se suscite alrededor de figuras como la de la inspección.

No habiendo, de momento, normas imperativas u obligatorias que garanticen la efectiva cooperación entre autoridades del mismo nivel (autoridades nacionales de competencia), y, por tanto, no instaurando exigencias mínimas que les obliguen a (i) notificar a sus pares acerca de nuevos asuntos a su cargo; (ii) prestar asistencia administrativa en diligencias como la de inspección más allá del ámbito vertical que les une con la Comisión, o incluso, (iii) informar a las otras autoridades del nivel nacional acerca de la decisión por la cual se ordena una diligencia o se extraen conclusiones de la misma, se está empoderando tácitamente a los Enforcement Bodies no comunitarios a colaborar única y exclusivamente cuando el curso de los procesos a su cargo encuentre un beneficio en razón de aquel marco de actuación.

Tal vez con el ánimo de favorecer la relación flexible y pragmática al interior de la naciente Red Europea de Autoridades de la Competencia, se pretendió no plantear normas imperativas con un efecto de «amarre» que pudiesen dificultar, en un asunto particular que lo ameritase, una actuación diversa, y, en consecuencia, se decidió que en la comunicación sobre la cooperación en la Red de Autoridades de Competencia podrían quedar delimitados ciertos aspectos de forma no imperativa, toda vez que dicho instrumento no plantea obligación alguna, máxime cuando aún está latente la falta de claridad acerca de la anuencia de los países miembros al firmarlo.

El éxito de la facultad de llevar a cabo inspecciones objeto de un proceso en torno a las normas de libre competencia requiere la unificación de conceptos a nivel comunitario, tanto en lo referido a la posición de colaboración de los demás Enforcement Bodies involucrados, como en aquello referente a los parámetros reguladores de algunos principios básicos de defensa relacionados con el secreto profesional y la posibilidad de guardar silencio y no autoinculparse.

La disposición de concepciones jurisprudenciales poco divergentes por parte de las Cortes Europeas y la estructuración de un sendero similar que no dejase en manos de la interpretación de un asunto a otro la existencia de los privilegios nombrados en el párrafo anterior garantizaría que el resultado de la diligencia de inspección aportara unos excedentes cada vez mayores al proceso de defensa de la competencia y que sus resultados fuesen mucho mas enriquecedores a forma de precedentes. 
Es necesario el asentamiento institucional y funcional, y hasta tanto aquéllos no sean una realidad, la inspección seguirá teniendo inconvenientes para materializarse con los niveles de sorpresa que requiere para, efectivamente, lograr comprobar la distorsión del proceso competitivo y las conductas que la causan. En todo caso, un proceso que sin lugar a dudas a dado pasos importantes hacia su consolidación.

\section{BIBLIOGRAFÍA}

\section{Bibliografía}

Adrián Arnáiz, A. J., y Quijano González, J., «Procedimiento de aplicación de las reglas sobre competencia de los arts. 81 y 82 del Tratado de la Comunidad Europea», en L. A. Velasco SAn Pedro (coord.), Derecho europeo de la competencia (antitrust e intervenciones públicas), Valladolid, Lex Nova, 2005.

Allendesalazar Corcho, R., «Confidencialidad de las comunicaciones abogado y cliente y eficacia de la labor inspectora: dos principios a la búsqueda de un equilibrio», Gaceta Jurídica de la Unión Europea y de la Competencia, núm. 7 (enero-febrero de 2009).

Barents, R., Directory of EC case Law on Competition, Alphen aan den Rijn (Holanda), Kluwer Law International, 2007.

Bellamy, C.; Child, G., y Picañol, E., Derecho de la competencia en el mercado común, Madrid, Civitas, 1992.

Brammer, S., Co-operation Between National Competition Agencies in the Enforcement of EC Competition Law, Oxford-Portland, Hart Publishing, 2009.

Calvo Caravaca, A. L., Derecho antitrust europeo, t. I, Parte General. La competencia, Madrid, Colex, 2009.

Christoforou, T., «Protection of legal privilege in ECC competition law: The imperfections of a case», Fordham International Law Journal, vol. 9, núm. 1 (1985).

Concepción Rodríguez, J. L.; Gimeno-Bayón Cobos, R., y Rodríguez Vega, L., «Coordinación entre los tribunales, la Comisión y las autoridades nacionales en la aplicación de los arts. 81 y 82 del TCE», Cuadernos de Derecho Judicial, núm. 17 (2004).

Consejo Europeo, Reglamento 17/1962 del Consejo, de 6 de febrero de 1962, sobre primer reglamento de aplicación de los arts. 81 y 82 del TCE.

- Reglamento (CE) núm. 1/2003, relativo a la aplicación de las normas sobre competencia previstas en los arts. 101 y 102 del Tratado de funcionamiento de la Unión Europea.

Craig, P., y De Burca, G., EU Law. Text, cases and materials, 4. ed., New York, Oxford University Press, 2008. 
CRANE, D., «Private enforcement against international cártels in Latin America: a US Perspective», en Competition law and policy in Latin America, Oxford, Hart Publishing, 2009.

Creus Carreras, A., y Amador Peñate, O., «Procedimiento administrativo ante la Comisión Europea y control jurisdiccional del TJCE», en J. M. ${ }^{a}$ BENEYTO Pérez-Cerdá y J. Maillo González Orús (dirs.), Tratado de Derecho de la Competencia. Unión Europea y España, Madrid, Bosch, 2005.

Edward, D., «Confidentiality and privilege in the ECC context», National Law Journal, núm. 128 (1978).

FERNÁNDEZ LÓPEZ, J. M., «Los Juzgados de lo Mercantil ante el Derecho comunitario de la competencia», Anuario de la Competencia, núm. 1 (2003).

FuRSE, M., Competition law of the EC and UK, New York, Oxford University Press, 2006.

GIL IbáÑ̃EZ, J. L., «La Comisión y la aplicación del Derecho comunitario de la competencia», en L. GARRIDO ESPÁ (ed.), La defensa de la competencia por los órganos judiciales: el Reglamento (CE) 1/2003, Madrid, Consejo General del Poder Judicial, 2005.

Gippini-Fournier, E., «Legal Professional Privilege in Competition Proceedings before the European Commission: Beyond the cursory Glance», Fordham International Law Journal, vol. 28, Book 4 (2005).

Gray, M.; Lester, M.; Darbon, C.; Facenna, G.; Brown, C., y Holmes, E., Eu Law Competition law: procedures and remedies, Richmond, Oxford University Press, 2006.

Jones, A., y Sufrin, B., EC Competition Law. Text, Cases and Material, New York, Oxford University Press, 2008.

JoshuA, J., «It's a Privilege: Managing Legal Privilege in Multijurisdictional Antitrust Investigations», en Competition Law Insight, 11 de diciembre de 2007.

Korah, V., An introductory guide to EC Law and practice, Oxford-Portland, Hart Publishing, 2007.

LEÓN JiMÉNEZ, R., «Los derechos fundamentales de las empresas en el procedimiento de competencia comunitario», en L. Ortiz Blanco y A. PAscual Sequeros (coords.), Derecho de la competencia europeo y español, vol. III, Madrid, Dykinson, 2002.

MacCulloch, A., «The privilege against self-incrimination in competition investigations: theoretical foundations and practical implications», Legal Studies, vol. 26, núm. 2 (junio de 2006).

PACE, L. F., European Antitrust Law. Prohibitions, Merger Control and Procedures, Edward Elgar Publishing, Cheltenham, 2007.

Pagone, G. T, «Legal profesional privilege in the European Communities: The AM \& s Case and Australian Law», International and Comparative Law Quarterly, núm. 33 (1984).

Pascual y Vicente, J., «La nueva política comunitaria europea de control de conductas y su repercusión en España», Anuario de la Competencia, núm. 1 (2003). 
POlSter, S., «Access to cártel evidence as a key to enhanced private enforcement: The Austrian example», Chambers Client Report, núm. 25 (2008).

Segal, I. R., y Whinston, M., «Public vs. private enforcement of antitrust law: A Survey», Working paper, núm. 335 (2006).

SirAgusa, M., «A critical review of the white paper on the reform of the EC Competition Law Enforcement rules», en B. E. HAwK (ed.), 1999 Proceedings of the Fordham Corporate Law Institute, New York, Juris Publishing, 2000.

Soto Pineda, J. A., Vias de aplicación del Derecho de la competencia, Madrid, Universidad Autónoma de Madrid, 2012.

Steward, S., y Vaughan, D., «Does legal profesional privilege exist in the ECC?», Law Society Gazette, núm. 1207 (1975).

SudERow, J., «Nota sobre la Sentencia del TJCE Akzo Nobel y otros de 14 de septiembre de 2010: límites al privilegio legal de las comunicaciones entre abogados y sus clientes», Cuadernos de Derecho Transnacional, vol. 3, núm. 1 (marzo de 2011).

TAndeau de Marsac, M. X., «Professional Privilege (confidentiality)», International Bar Journal (noviembre de 1976).

Van Bael, I., y Bellis, J.-F., Competition Law of the European Community, Alphen aan den Rijn (Holanda), Kluwer Law International, 2010.

VAN OverbeeK, W., «The Reight to remain silent in competition investigations: The Funke decision of the Court of Human Rights Makes Revision of the ECJ's Case Law Necessary», European Competition Law Review, vol. 15, núm. 3 (1994).

Vesterdorf, B., «Legal Professional Privilege and the Privilege Against Self-Incrimination in EC Law: Recent Developments and Current Issues», Fordham International law journal, vol. 28, núm. 4.

WAINWRIGHT, R., «Application of EC competition rules by national courts», artículo presentado en la conferencia «Antitrust reform in Europe: A year in practice», organizada de forma conjunta por el Colegio de Abogados Internacional y la Comisión Europea, Bruselas, 9-11 de marzo de 2005.

Whish, R., Competition Law, London, Oxford University Press, 2008.

WiLs, W. P. J, Efficiency and European antitrust enforcement, Portland, Hart Publishing, 2008.

WILLIS, P., «The Privilege against self-incrimination in competition investigations», artículo presentado en el Competition, Regulation and Trade Group Taylor Wessing, 27 de enero de 2006.

\section{Jurisprudencia y resoluciones europeas}

Comunicación de la Comisión relativa a la cooperación entre la Comisión y los órganos jurisdiccionales de los Estados miembros de la Unión Europea para la aplicación de los arts. 81 y $82 \mathrm{CE}$. 
Sentencia del Tribunal de Justicia de las Comunidades Europeas de 21 de septiembre de 1989, asuntos acumulados 46/87 y 227/88, Hoechst A. G. vs. la Comisión de las Comunidades Europeas.

Sentencia del Tribunal de Justicia de las Comunidades Europeas, Sala Quinta, de 19 de mayo de 1994, asunto C-36/92 P, Samenwerkende Elektriciteits-Produktiebedrijuen NV (SEP) vs. la Comisión de las Comunidades Europeas.

Sentencia del Tribunal de Justicia de las Comunidades Europeas, Sala Quinta, de 24 de junio de 1986, asunto 53/85, AKZO Chemie BV vs. la Comisión de las Comunidades Europeas.

Sentencia del Tribunal de Justicia de las Comunidades Europeas de 29 de junio de 2006, asunto C-301/04 P, La Comisión de las Comunidades Europeas vs. SGL Carbon AG.

Sentencia del Tribunal de Justicia de las Comunidades Europeas de 18 de octubre de 1989, asunto 374/87, Orkem S. A. vs. la Comisión de las Comunidades Europeas.

Decisión de la Comisión Europea 80/334/CEE, de 20 de diciembre de 1979, por la que se impuso una multa en razón del art. 15 del Reglamento núm. 17 a la empresa Fabbrica Pisana.

Sentencia del Tribunal de Justicia de las Comunidades Europeas de 22 de octubre de 2002, asunto C-94/2000, Roquette Frères S. A. vs. Directeur général de la concurrence, de la consommation et de la répression des fraudes, y la Comisión de las Comunidades Europeas (en lo sucesivo Roquette Frères).

Sentencia del Tribunal de Justicia de las Comunidades Europeas de 26 de junio de 1980, asunto 136/79, National Panasonic (UK) limited vs. la Comisión de las Comunidades Europeas.

Sentencia del Tribunal de Justicia de las Comunidades Europeas de 18 de octubre de 1989, asunto 27/88, Solvay vs. la Comisión de las Comunidades Europeas.

Sentencia del Tribunal de Primera Instancia, Sala Primera ampliada, de 20 de febrero de 2001, asunto T-112/98, Mannesmannröbren-Werke AG vs. la Comisión de las Comunidades Europeas.

Sentencia del Tribunal de Justicia de las Comunidades Europeas, La Comisión de las Comunidades Europeas vs. SGL Carbón AG y otros.

Decisión de la Comisión Europea de 18 de julio de 2001, relativa al procedimiento de conformidad con el art. 81 del Tratado CE y el art. 53 del Acuerdo sobre el Espacio Económico Europeo, asuntos COMP.D.2 37.444, SAS/Maersk Air, y COMP.D.2 37.386, SUN-Air vs. SAS y Maersk Air.

Sentencia del Tribunal de Justicia de las Comunidades Europeas de 18 de mayo de 1982 , asunto $155 / 79$.

Sentencia del Tribunal de Primera Instancia de 12 de diciembre de 1991, asunto T-30/89, Hilti AG vs. la Comisión de las Comunidades Europeas. 
Sentencia del Tribunal de Justicia de las Comunidades Europeas de 17 de octubre de 1989, asunto 85/87, Dow Benelux NV vs. la Comisión de las Comunidades Europeas.

Sentencia del Tribunal de Primera Instancia de 17 de septiembre de 2007, asuntos acumulados T-125/03 y T-253/03.

Sentencia del Tribunal de Justicia de las Comunidades Europeas de 18 de mayo de 1982, asunto 155/79, Australian Mining \& Smelting Europe Limited vs. la Comisión de las Comunidades Europeas.

Sentencia del Tribunal de Justicia de las Comunidades Europeas de 16 de septiembre de 1999, asunto C-22/98, Solicitud de decisión prejudicial en el proceso penal contra Jean Claude Becu, Annie Verweire, Smeg NV y Adia Interim NV (en lo sucesivo Jean Claude Becu y otros).

Sentencia del Tribunal de Primera Instancia de 8 de diciembre de 1999, asunto C-79/59, Euro-Lex European Law Expertise GmbH vs. la Oficina de Armonización del Mercado Interior (marcas, dibujos y modelos).

Decisión de la Comisión de 28 de enero de 1998, relativa a un procedimiento de aplicación del art. 85 del Tratado CE, caso IV/35.733, Volkswagen vs. la Comisión de las Comunidades Europeas.

Sentencia del Tribunal de Justicia de las Comunidades Europeas de 9 de noviembre de 1983, asunto 322/81, NV Nederlandsche Banden Industrie Michelin vs. la Comisión de las Comunidades Europeas.

Sentencia del Tribunal de Primera Instancia de 25 de octubre de 2005, asunto T-5/02, Tetra Laval BV vs. la Comisión de las Comunidades Europeas.

Sentencia del Tribunal de Justicia de las Comunidades Europeas de 30 de octubre de 1978, asuntos acumulados 209/78 R a 215/78 R y 218/78 R, Heintz van Landewyck SARL y otros vs. la Comisión de las Comunidades Europeas.

Sentencia del Tribunal de Justicia de las Comunidades Europeas de 7 de noviembre de 1985, asunto 145/83, Stanley George Adams vs. la Comisión de las Comunidades Europeas.

Sentencia del Tribunal de Justicia de las Comunidades Europeas de 6 de julio de 2000, asunto T-62/98, Volkswagen AG vs. la Comisión de las Comunidades Europeas.

Sentencia del Tribunal de Justicia de las Comunidades Europeas, asunto T-198/03, Bank Austria Creditanstalt vs. la Comisión de las Comunidades Europeas.

Sentencia del Tribunal de Primera Instancia de 29 de abril de 2004, asuntos acumulados T-236/01, T-239/01, T-244/01, T-245/01, T-246/01, T-251/01 у T-252/01, Tokai Carbon Co. Ltd., SGL Carbon AG, Nippon Carbon Co. Ltd. y otros vs. la Comisión de las Comunidades Europeas.

Sentencia del Tribunal de Justicia de las Comunidades Europeas, asunto C-301/04 P, La Comisión de las Comunidades Europeas vs. SGL Carbón AG y otros. 
Sentencia del Tribunal de Primera Instancia de 20 de febrero de 2001, asunto T-112/98, Mannesmann-Robrenwerke AG vs. la Comisión de las Comunidades Europeas.

Sentencia del Tribunal de Primera Instancia de 21 de junio de 2006, asunto T-47/02, Danzer vs. el Consejo de la Unión Europea.

Sentencia del Tribunal de Primera Instancia, apartado 734, Cimenteries CBR y otros vs. la Comisión de las Comunidades Europeas.

Sentencia del Tribunal de Primera Instancia, apartado 74, Société générale vs. la Comisión de las Comunidades Europeas. 